NBER WORKING PAPER SERIES

\title{
WORKING THEIR WAY UP? US IMMIGRANTS' CHANGING LABOR MARKET ASSIMILATION IN THE AGE OF MASS MIGRATION
}

\author{
William J. Collins \\ Ariell Zimran \\ Working Paper 26414 \\ http://www.nber.org/papers/w26414 \\ NATIONAL BUREAU OF ECONOMIC RESEARCH \\ 1050 Massachusetts Avenue \\ Cambridge, MA 02138 \\ October 2019, Revised December 2021
}

For helpful comments and discussions, the authors thank the editors, Ilyana Kuziemko and Seema Jayachandran, as well as two anonymous referees, Ran Abramitzky, Jeremy Atack, Leah Boustan, Joseph Ferrie, Martin Fiszbein, Chris Minns, Joel Mokyr, Zachary Ward, and seminar and conference participants at the Economic History Association Annual Meetings, the Federal Reserve Bank of Minneapolis, the Hoover Institution, the NBER-DAE Summer Institute, Northwestern University, the University of Pittsburgh, and Vanderbilt University. Work on this paper was completed while Ariell Zimran was a W. Glenn Campbell and Rita Ricardo-Campbell National Fellow and the William C. Bark National Fellow at the Hoover Institution, Stanford University, and a Visiting Scholar at the Opportunity and Inclusive Growth Institute at the Federal Reserve Bank of Minneapolis; funding from both institutions is gratefully acknowledged. The views expressed herein are those of the authors and not necessarily those of the Federal Reserve Bank of Minneapolis, the Federal Reserve System, or the National Bureau of Economic Research. Collins is the Terence E. Adderley Jr. Professor of Economics at Vanderbilt University and a Research Associate of the NBER. Zimran is an Assistant Professor of Economics at Vanderbilt University and a Faculty Research Fellow of the NBER.

NBER working papers are circulated for discussion and comment purposes. They have not been peer-reviewed or been subject to the review by the NBER Board of Directors that accompanies official NBER publications.

(C) 2019 by William J. Collins and Ariell Zimran. All rights reserved. Short sections of text, not to exceed two paragraphs, may be quoted without explicit permission provided that full credit, including $\odot$ notice, is given to the source. 
Working Their Way Up? US Immigrants' Changing Labor Market Assimilation in the Age of Mass Migration

William J. Collins and Ariell Zimran

NBER Working Paper No. 26414

October 2019, Revised December 2021

JEL No. J61,J62,N11,N12,N13,N14

\begin{abstract}
Whether immigrants advance in labor markets during their lifetime relative to natives is a fundamental question in the economics of immigration. We examine linked census records for five cohorts, spanning 1850-1940, when immigration to the United States was at its peak. We find a U-shaped pattern of assimilation: immigrants were "catching up" to natives in the early and later cohorts, but not in between. This change was not due to shifts in immigrants' source countries. Instead, it was rooted in men's early-career occupations, which we associate with structural change, strengthening complementarities, and large immigration waves in the 1840s and 1900s.
\end{abstract}

William J. Collins

Department of Economics

Vanderbilt University

VU Station B \#351819

2301 Vanderbilt Place

Nashville, TN 37235-1819

and NBER

william.collins@vanderbilt.edu

Ariell Zimran

Department of Economics

Vanderbilt University

2301 Vanderbilt Place

Nashville, TN 37235

and NBER

ariell.zimran@vanderbilt.edu

A data appendix is available at http://www.nber.org/data-appendix/w26414 


\section{Introduction}

The 30 million European immigrants who entered the United States in the century before 1921 's closing of the "Golden Door" powerfully shaped American economic, demographic, and political development. ${ }^{1}$ Their experiences during this Age of Mass Migration form a cornerstone of broad interpretations of American history, especially regarding the opportunity for and realization of upward economic mobility. The idea that the United States is (or was) the "land of opportunity" goes hand-in-hand with the idea that the United States is "a nation of immigrants." These ideas, in turn, continue to inform contemporary views on immigration and social policy. A widely held and influential view is that European immigrants entered the American economy in low-paying occupations but experienced rapid economic and cultural assimilation despite facing discrimination and receiving little aid (Kennedy 1964; Smith et al. 2018). ${ }^{2}$ Against this idealized historical benchmark, some question the capacity or willingness of many of today's immigrants to assimilate, and see this as a rationale for more restrictive and selective policies (e.g., Kelly 2018; Martin 2019). ${ }^{3}$

In this paper, we test the soundness of this view of historical immigrants' experiences. We show that assimilation patterns, observed over individual workers' careers, changed significantly over the Age of Mass Migration: the first and last cohorts of European immigrants in the Age of Mass Migration did substantially narrow gaps in economic status relative to those born in the United States (henceforth natives), but other cohorts of European immigrants did not. We also investigate why this pattern changed and find that the dramatic shift of countries-of-origin within Europe (toward the South and East) had little to do with it. The answer instead lies in the shifting allocations of young men across occupations, which in turn reflected structural change in the economy, strengthening complementarities, and the timing of large waves of immigration.

Many scholars have studied immigrants' labor market outcomes and how they change with time spent in the United States in both historical settings and in recent decades. ${ }^{4}$ Indeed, whether and

\footnotetext{
${ }^{1}$ This refers to the 1921 Emergency Quota Act, the first quantitative restriction on European immigration. Other dates cited as the end of the Age of Mass Migration are 1914 (the outbreak of World War I), 1917 (the imposition of the literacy test) and 1924 (the National Origins Act, which tightened quotas imposed in 1921). ${ }^{2}$ In the 1994 General Social Survey, 80 percent of respondents agreed or strongly agreed with the statement that, "The Irish, Italians, Jews, and many other minorities overcame prejudice and worked their way up. Today's immigrants should do the same without any special favors" (Smith et al. 2018).

${ }^{3}$ Ken Cuccinelli, at the time the acting head of US Citizenship and Immigration Services, stated that he would welcome immigrants "who can stand on their own two feet, be self-sufficient, pull themselves up by their bootstraps - again, as in the American tradition. My Italian-Irish heritage looks back at that. Most people in America look back at that. And that's what we expect going forward" (Martin 2019).

${ }^{4}$ We study intra-generational changes, not inter-generational assimilation. See Blau (1980), Hannon (1982), Eichengreen and Gemery (1986), Hanes (1996), Hatton (1997, 2000), Ferrie (1999), Minns (2000), and Abramitzky, Boustan, and Eriksson (2014) for historical studies. See Chiswick (1978), Borjas (1985, 2014,
} 
how quickly immigrants advance in labor markets relative to natives is one of the core questions in the economics of immigration (e.g., Borjas 2014; Abramitzky and Boustan 2017). The value of historical perspective on this question is widely recognized in this literature, but data limitations have obscured scholars' view of what actually happened during the Age of Mass Migration. This period, on which we focus, predates the design and implementation of national longitudinal surveys or largescale and representative administrative records. Instead, we conduct our analyses with individuallevel linked census records for the periods 1850-1880, 1870-1900, 1880-1910, 1900-1930, and 19101940. The datasets include non-southern, native- or European-born white men, aged 18-30 in the first year of the linkage span. The panel structure of the linked data avoids biases that arise in assimilation studies that use cross-sectional data, such as changing cohort quality and selective return migration (Chiswick 1978; Borjas 1985; Lubotsky 2007; Abramitzky, Boustan, and Eriksson 2014). In addition, the datasets are sufficiently large that we can study outcomes for immigrants from specific source countries. We show that our results are not sensitive to the linkage method we employ, which gives us confidence that we can reliably compare immigrants' and natives' lifecycle labor market outcomes over the full span of the Age of Mass Migration for the first time.

A challenge to studying historical labor market outcomes is that individual wage information is not available in nationally representative data sources. The census did not collect wage data until 1940 and even then omitted earnings for farmers and other self-employed workers. Therefore, as is common in such settings, we focus on workers' occupational status. We start by characterizing occupational status according to broad and simple categories - unskilled, operative, craft, farmer, and white collar. Then, we make full use of the censuses' detailed (three-digit) occupational information to rank workers (described in detail in section 3).

Our first main finding is that there were important changes in immigrants' occupational assimilation patterns over the Age of Mass Migration. In terms of their distribution over broad occupational categories, immigrants in every cohort that we study became more like natives, indicating that, from this coarse perspective, a form of economic assimilation occurred. From a more detailed and rank-based perspective, the assimilation pattern is U-shaped. The earliest (1850-1880) and latest cohorts (1910-1940) experienced substantial gains relative to natives, whereas immigrants in the three middle cohorts did not (though they also started closer to natives). Thus, although patterns in some periods support the view that immigrants started behind natives in labor markets but

2015), Card (2005), Lubotsky (2007), Duncan and Trejo (2012), Villarreal and Tamborini (2018), Cassidy (2019), Bansak, Simpson, and Zavodny (2020), and Peri and Rutledge (2021) for studies of more recent decades. 
gained ground with time, the experience in other periods was quite different. Our result for the 19001930 cohort is consistent with Abramitzky, Boustan, and Eriksson (2014), who study 1900-1920, which is reassuring since we employ different methods and data. But by extending the analysis to several different cohorts, both earlier and later so that we cover the entire Age of Mass Migration, we develop a broader and more complex view of European immigrants' labor market experiences.

The changing patterns of immigrants' assimilation require investigation, and we consider several possibilities. The paper's second main finding is that changes in immigrants' upgrading patterns relative to natives were not the product of changes in immigrants' European source countries, as they shifted away from the North and West and toward the South and East. This finding, together with the strong "catching up" exhibited by the 1910-1940 cohort, is important in light of influential claims by social scientists, commentators, and policymakers in the early twentieth century that immigrants from the "new" sources were "inferior" to those who had previously come from the "old" sources. ${ }^{5}$ Such claims helped to motivate the design and implementation of immigration restrictions in the 1920s that were severely biased against potential immigrants from eastern and southern Europe and remained in place until the 1960s (Walker 1896; CommissionerGeneral of Immigration 1903; Zolberg 2006; Benton-Cohen 2018).

Instead, we show that changes in immigrants' relative upgrading depended strongly upon changes in young workers' occupational distributions. In 1850, young natives in our sample were relatively concentrated in farming, whereas young immigrants were relatively concentrated in unskilled labor. This is important because young men engaged in unskilled labor, whether immigrant or native, experienced high rates of occupational upgrading over their lifetimes, whereas farmers experienced relatively little. Thus, although we show that natives in all periods upgraded at least as much as immigrants did conditional on the initial year's occupational category, ${ }^{6}$ the relative concentration of immigrants in unskilled (and high upgrading) occupations in 1850 underpinned convergence in occupational status in the aggregate.

Later in the nineteenth century, the differences in occupations between cohorts of young immigrant and native workers declined. Unskilled labor became more common for young natives, and farming became more common for young immigrants. The combination of smaller immigrantnative differences in initial-year occupations and natives' continued advantage in upgrading

\footnotetext{
${ }^{5}$ More specifically, the "old" sources were primarily Germany, Britain, and Ireland. The "new" sources were primarily Italy, the Russian Empire, and the Austro-Hungarian Empire.

${ }^{6}$ This is a novel finding that contradicts the notion that European immigrants were at first under-placed in labor markets relative to natives with similar productive abilities and then gained ground rapidly.
} 
conditional on initial-year occupations diminished the relative gains for immigrants in the aggregate.

Finally, near the end of the Age of Mass Migration, the 1910 cohort of young immigrants was once again distributed over occupations quite differently than young natives. In particular, young immigrants were again strongly concentrated in unskilled (and high-upgrading) occupations, whereas natives grew more concentrated in white-collar jobs. The widening difference in initial occupations once again underpinned substantial gains for immigrants relative to natives after 1910 .

An in-depth explanation for the changing occupational distribution of each cohort of young men is beyond the scope of the paper. But the changes are consistent with two important forces acting on the economy during the Age of Mass Migration. The first is the structural transformation of the economy, which shifted new cohorts of young natives out of farming, into nonfarm labor, and eventually into higher skilled white-collar occupations. This trend may have been reinforced by strengthening complementarities between capital and skill and between immigrants and natives (Lafortune, Lewis, and Tessada 2019; Tabellini 2020). The second is the arrival of particularly large cohorts of immigrants in the 1840s and 1900s (just prior to the 1850 and 1910 censuses), driven in part by events and changes in Europe; these cohorts were initially heavily concentrated in unskilled occupations.

This paper advances the study of immigration in several ways. First, it broadens our view of immigrants' labor market assimilation in the United States, and it contrasts with the literature on assimilation since the 1960s. As in the Age of Mass Migration, the modern era has been characterized by changing assimilation patterns (Borjas 2014, ch. 2; Lubotsky 2011); specifically, declines in the initial status of immigrants relative to natives have been accompanied by less rapid assimilation (Bansak, Simpson, and Zavodny, p. 130). But in the Age of Mass Migration, the cohorts who started furthest behind natives experienced the greatest upward mobility. Second, the paper's findings revise our knowledge of key facts about immigrants' assimilation in American history. This is important, in part, because the experiences of European immigrants in the Age of Mass Migration are still commonly referenced in immigration policy debates, often on the basis of personal anecdotes rather than systematic evidence. Finally, the paper provides an explanation for why certain assimilation patterns prevailed and changed over time during the Age of Mass Migration. ${ }^{7}$ Favorable assimilation patterns, when they occurred, were rooted in sharp differences in young natives and

\footnotetext{
${ }^{7}$ In advancing our understanding of assimilation in the Age of Mass Migration, this paper complements research by Hatton and Williamson (1998), Ferrie (1999), Abramitzky, Boustan, and Eriksson (2014), Abramitzky et al. (2021b), Collins and Zimran (2019), Pérez (2021), and Ward (2020) among others. Abramitzky and Boustan (2017) and Hatton and Ward (2019) survey this literature.
} 
immigrants occupational distributions; they were not the result of particular immigrant cohorts' superior skills, advantageous county-of-origin heritage, or exceptional occupational mobility compared to natives. This view challenges prevalent perceptions regarding the realization and sources of European immigrants' upward mobility—myths that continue to influence thinking about American history and policy.

\section{Background}

\section{Immigrants in the US labor market during the Age of Mass Migration}

Figure 1 shows the volume of annual European immigration to the United States (relative to the population). ${ }^{8}$ During this time, there were minimal restrictions on immigration from Europe. This openness allowed for three main waves of European immigration to the United States. The first was a surge in immigration during the 1840 s and continuing into the $1850 \mathrm{~s}$, reflecting reduced costs of transatlantic travel, the Irish Famine, and the beginning of large-scale migration from Germany. Mass immigration waned in the 1860s before resuming at a lower (but still high) per capita level for the rest of the nineteenth century. There was another surge in mass immigration around 1900, but by this time the main source countries had shifted from northern and western Europe to the south and east. ${ }^{9}$ World War I interrupted the flow of immigrants, but only temporarily. After adding a literacy test for immigrants in 1917, the United States implemented restrictive immigration quotas in 1921 and 1924, culminating decades of intense debate over immigration policy (Hutchinson 1981; Goldin 1994; Benton-Cohen 2018). In addition to imposing restrictions on annual immigration totals, the country-specific quotas were severely biased against potential migrants from southern and eastern Europe and effectively barred immigration by Asians. With minor modifications, this system governed entry to the United States until the Hart-Celler Act of 1965.

For perspective on the allocation of workers across occupations, Figure 2 shows the share of white male natives and European immigrants, ages 18 to 65, working in three broad occupational categories — farmers, unskilled labor, and white-collar occupations - from 1850 to $1940 .{ }^{10}$ The

\footnotetext{
${ }^{8}$ We focus on European migration because it accounts for nearly 90 percent of the total inflows to the US prior to 1914 (Abramitzky and Boustan 2017, Figure 2, p. 1316), because it was the subject of the main policy debates in the nineteenth and twentieth centuries, and because it was effectively unconstrained prior to World War I (as opposed to Asian immigration, which was effectively banned by the Chinese Exclusion Act of 1882 and the "Gentlemen's Agreement" of 1907).

${ }^{9}$ See Gould (1980), Hatton and Williamson (1998), and Spitzer and Zimran (2021) for a discussion of the timing, rapidity, and causes of this shift.

${ }^{10}$ The unskilled category includes service workers, farm laborers, and laborers, but excludes individuals working as farm laborers on the family farm. For more details, see our discussion in section 3.
} 
predominance of natives in farming and immigrants in unskilled work in 1850 is immediately apparent, as is the secular decline in farming as a share of the native labor force (and of the immigrant labor force after 1880). Among natives, there was also a rise in the shares of unskilled and white-collar occupations, with white-collar occupations surpassing farmers by 1910. Immigrants also experienced a rise in white-collar employment, but were always primarily unskilled laborers. From 1850 to 1880 , there is convergence in the share of farmers in each group, and from then on, the gaps between immigrants' and natives' shares in farming and unskilled jobs were smaller than in the mid-nineteenth century. But these patterns of convergence are difficult, and possibly misleading, to interpret as evidence of labor market assimilation. Due to the continuous inflow and outflow (i.e., return migration) of immigrants, cross-sectional data sources provide little useful insight into how immigrants who stayed in the United States fared over their lifecycle relative to natives. This has been a central challenge to studying immigrants' labor market outcomes and the process of assimilation during the Age of Mass Migration.

Data shortcomings, of course, did not forestall policy debates and decisions centered on immigrants' assimilation in the labor market and in other social dimensions. Natives' concerns over immigrants' poverty, lack of skills, insularity, and religion are at least as old as the onset of mass immigration from Ireland (Higham 1955; Anbinder 1992; Alsan, Eriksson, and Niemesh 2020). Around 1900, the shift in source countries to southern and eastern Europe renewed vigorous debates over immigration policy (Goldin 1994; Williamson 1998; Benton-Cohen 2018). By this time, a common argument for restricting European immigration involved unfavorable comparisons of the "new immigrants" to the "old immigrants," where "new" and "old" referred to place of origin. Francis A. Walker, the first president of the American Economic Association, characterized the "new" immigrants as "beaten men from beaten races; representing the worst failures in the struggle for existence" (Walker 1896). ${ }^{11}$ The Commissioner-General of Immigration bemoaned the "new" immigrants' propensity for settling in urban areas, viewing this as evidence of their low quality in comparison with earlier migrants (Commissioner-General of Immigration 1903, p. 70). ${ }^{12}$ In 1907, Congress authorized the era's most influential study of immigrants - the Dillingham Commission

\footnotetext{
${ }^{11}$ Later, Irving Fisher, another president of the AEA, who had come to embrace eugenics and promote immigration restriction, wrote, "The core problem of immigration is one of race and eugenics..." (1921, p. 226; cited by Benton-Cohen 2018, p. 115).

${ }^{12}$ Commissioner Williams wrote: "Notwithstanding the well-known demand for agricultural labor in the Western States, thousands of foreigners keep pouring into our cities, declining to go where they might be wanted because they are neither physically nor mentally fitted to go to these undeveloped parts of our country and do as did the early settlers from northern Europe" (1903, p. 70). See Willcox (1906) for discussion of this issue. Zimran (2021) studies this issue using full-count census data.
} 
Reports. The Commission's policy recommendations included implementing a literacy test and source-specific quotas, and continuing bans on Asian immigration (US Congress 1911), each of which eventually became law (Benton-Cohen 2018). ${ }^{13}$

Econometric analyses, often based on tables from the Dillingham Commission Reports or cross-sectional microdata from specific industries and states, have produced mixed evidence as to whether nineteenth-century immigrants improved their status relative to natives as they gained labor market experience (Blau 1980; Hannon 1982; Eichengreen and Gemery 1986; Hanes 1996; Hatton 1997). Minns (2000) is notable in that he shifted attention to census microdata for 1900 and 1910 , which provided a more geographically comprehensive view, and found evidence consistent with occupational gains for immigrants relative to natives in nonfarm employment.

More recently and most closely related to our work, Abramitzky, Boustan, and Eriksson (2014) extended methods pioneered by Ferrie $(1996,1999)$ to construct a panel dataset of immigrants and natives between 1900 and 1920. Focusing on average immigrant-native differences in occupational status and their evolution with immigrants' time in the United States, they found that immigrants entered the US economy at approximately the same occupational status as natives and experienced almost no differential gains. They attribute prior findings of immigrants' labor market assimilation in this period to data deficiencies that are addressed by the use of panel data. Relative to the work of Abramitzky, Boustan, and Eriksson (2014), we significantly expand the temporal coverage to include the entirety of the Age of Mass Migration. Doing so reveals fundamental changes in overall assimilation patterns. The new datasets also enable us to make an important advance by explaining why patterns of occupational upgrading changed.

\section{Changes in immigrant assimilation in recent decades}

In addition to illuminating an important period in the development of the American economy and society, our findings also relate directly to (and contrast with) the literature concerned with modern immigrants' labor market assimilation in the United States. A key result in this literature is that assimilation, measured in terms of immigrants' wage gains relative to those of natives, has declined since the passage of the Hart-Celler Act in 1965 (Borjas 2014, 2015). This decline was accompanied by an increase in the gap between immigrants and natives at the time of arrival (Bansak, Simpson, and Zavodny 2020, p. 130).

\footnotetext{
${ }^{13}$ Hourwich (1912) and Douglas (1919) published critiques of the reports and of popular summaries of the Commission's work, most notably Jenks and Lauck's (1912) book, The Immigration Problem.
} 
Borjas (2015) evaluates several potential explanations for the decline in immigrant assimilation. He argues that this pattern is not the result of changing opportunities for upward mobility arising from macroeconomic conditions, changes in the country-of-origin distribution, immigrants' destination choices, or selection biases. Instead, he attributes the assimilation slowdown to declines in the rate at which immigrants gain English proficiency, which he connects in turn to the rapid growth of specific immigrant groups. ${ }^{14}$

Peri and Rutledge (2021) point out, however, that a similar decline in assimilation is not observed among migrants from Mexico and Central America, and suggest that the changing sourcecountry composition of immigrants is, in fact, responsible for Borjas's (2015) findings — an argument that echoes the focus on changing source countries by commentators and policymakers in the early twentieth century.

Given historical data's lack of information on individuals' wages, and the limited data on changing immigrant assimilation in either the modern era or the Age of Mass Migration it is difficult to bridge the literatures on the two eras perfectly (see Abramitzky and Boustan 2017). But it is clear that scholars and policymakers of both eras have regarded immigrants' labor market assimilation (or lack thereof) as an important economic phenomenon with significant policy implications. Our paper contributes to this line of inquiry by spanning 1850-1940 in far more detail than previously available.

\section{Data}

\section{Linked census records}

Starting from the complete count census files (Ruggles et al. 2020), we constructed five datasets of linked census records, each spanning a 30-year period: 1850-1880, 1870-1900, 18801910, 1900-1930, and 1910-1940. Online Appendix B describes the procedure in detail and presents statistics regarding linkage rates and selection into the linked samples. Together, the datasets provide coverage for the entire Age of Mass Migration, including the significant change in source-country composition of immigrants around the beginning of the twentieth century.

We first observe men when they were 18-30 years old, and we observe them again in the 4860 age range. At each date, we observe the individual's occupation, which forms the basis for our analyses of immigrants' occupational status relative to natives. ${ }^{15}$ The data's panel structure is

\footnotetext{
${ }^{14}$ Villarreal and Tamborini (2018) challenge this finding, arguing that it is not robust to the use of longitudinal data (rather than the repeated cross-section data used by Borjas 2015).

${ }^{15}$ The focus on those 18-30 in the initial census captures individuals near the beginning of their careers while limiting the extent to which selective mortality over the 30 -year span will affect results.
} 
essential. Abramitzky, Boustan, and Eriksson (2014) show that cross-sectional or repeated crosssection data can generate spurious evidence of labor market assimilation due to changing arrivalcohort quality and negatively selected return migration. As in their work, our panel datasets avoid potential confounds by limiting attention to a fixed sample of men who remained in the United States. This design is appropriate for studies that are primarily interested in whether immigrants who stayed in the United States experienced relative improvements in labor market status or other aspects of assimilation. It is worth bearing in mind, however, that linked census data might not capture the experience of the "average immigrant" given that some returned to their country of origin or died before being observed a second time (Bandiera, Rasul, and Viarengo 2013).

The study's timeframe reflects the availability of census data. The 1850 census was the first to enumerate all free individuals rather than just household heads, and the first to inquire about place of birth. The 1940 census manuscripts are the most recent to have been released to the public. The set of linked datasets also reflects the absence of 1890's census manuscripts, which have not survived, and our decision to use 30-year linkage spans. This choice allows sufficient time to observe occupational upgrading over the lifecycle and lets us avoid the 1860 census, where the coding of occupations is incomplete. ${ }^{16}$

The linked datasets include white native- and European-born men who did not live in the South in either census year. This focuses on the native-born workers most comparable to immigrants in the Age of Mass Migration. We limit attention to non-southern men because few immigrants located in the South in this period and because the Civil War's impact on the South may confound comparisons that span the war. The limitation to men is due to the difficulty of accurately linking women over long spans due to name changes at marriage.

Several concerns arise in the use of linked census data (Bailey et al. 2020; Abramitzky et al. 2021a). First, non-random selection into linkage is common. For instance, individuals with higher human capital and more stable residence are typically more likely to be linked. To address this issue, we construct inverse probability weights that make the distribution of observables in each linked sample match (as closely as possible) that of the sample of men eligible for linkage (Online Appendix B). When possible, we weight the sample to match the population characteristics for white, non-southern men aged 44-64 in the latter year of each span, with the added restriction that immigrants must report having arrived before the span's first year. We choose to match the latter

\footnotetext{
${ }^{16}$ A number of the datasets released by Ruggles et al. (2020) are preliminary, but 1860 is problematic because the dataset does not (yet) report occupations for a large number of individuals for whom occupations were in fact listed in the original manuscripts.
} 
year because the initial year includes immigrants who would eventually return to their home countries. When immigrants' year of arrival is not reported in the latter year (1880 and 1940), we match the characteristics of the relevant population in the span's earlier year. This avoids the influence of subsequent immigrants on the latter year's sample composition, but might give too much weight to men who later left the United States. Low rates of return migration before 1880 make us unconcerned that selective return migration is an important factor in the 1850-1880 linked sample. But the inability to address return migration in our reweighting for the 1910-1940 sample is more concerning. We show below that any bias is insufficient to qualitatively change our results.

Second, some of the matches in linked samples may be false positives, which would lead to spurious changes in occupations over time. In our intra-generational context, this issue is less concerning than in studies of inter-generational mobility, where a key statistic of interest is the correlation between fathers' and sons' jobs. Instead, our focus is largely on changes in average occupational rankings for groups of men, which are less sensitive to false matches because they do not depend on the correlation between an individual's occupation in the first and the last period. Nonetheless, to limit false matches, we constructed the baseline links under relatively strict criteria. Moreover, in Online Appendix C, we repeat our analysis using even stricter matching criteria and find that the results are qualitatively similar.

Finally, one might be concerned that results are sensitive to some idiosyncrasy of the linkage method. ${ }^{17}$ To verify that this is not the case, Online Appendix $\mathrm{C}$ repeats our analyses using alternate linkage methods. Again, the results are qualitatively similar.

\section{Studying occupations to learn about labor market assimilation}

Occupational information was collected in each census beginning in 1850, enabling our analysis of occupational changes in both the nineteenth and the twentieth centuries in a fairly consistent manner. We rely on the detailed three-digit occupational coding provided by Ruggles et al. (2020). We begin by defining five broad classes of occupations - farmer, white collar, craft, operative, and unskilled. ${ }^{18}$ Our preliminary analysis entails simple comparisons (controlling only for

\footnotetext{
${ }^{17}$ For instance, our method makes use of string distances in selecting matches, whereas Abramitzky, Boustan, and Eriksson's (2014) does not.

${ }^{18}$ The broad categories are defined using IPUMS occ1950 codes: white collar [1, 100) and [200, 500); farmer $[100,200)$; craft $[500,600)$; operative $[600,700)$; unskilled $[700,970]$. The unskilled category includes service workers, farm laborers, and laborers. The 1900, 1910, and 1930 complete count data include a significant fraction whose occupation codes are "not yet classified" (code 979). Our baseline analyses omit these individuals. In Online Appendix D, we classify these individuals using the modal classification of the NYSIIS code of their occupational string. Our results are qualitatively unaffected by their inclusion.
} 
age) of the distributions of immigrants and natives across these occupational categories and of changes in these distributions over the men's lifecycle. This approach has the advantage of not requiring any assumptions about the relative standing of occupations, but of course it provides little insight into whether men improved their occupational status over time.

We then introduce rank measures of occupational status. The literature has often relied on an occupation-based "income score" derived from tables in the 1950 census. We prefer not to use this measure because of its temporal distance from our study period. Instead, we construct several alternative occupational scores. The first is based on the 1870 census questions about real and personal wealth (Collins and Zimran 2019; Ager, Boustan, and Eriksson 2021; Craig, Eriksson, and Niemesh 2019). We use the complete-count data for the 1870 census to compute average total wealth (the sum of real and personal wealth) within each detailed (three-digit) occupational cell for men aged 30 to $65 .{ }^{19}$ This produces an occupational wealth score that is similar in spirit to the occupational income score commonly used in studies of historical labor markets. We use this score to compute occupational ranks, which are expressed relative to all non-southern white men in the labor force (ages 18-64). ${ }^{20}$ Thus, for any given man, a change in rank over time depends on whether he changed occupations and on how the occupational distribution of all men in the labor force changed. We prefer the rank measure over the raw score because it is less sensitive to the specific cardinal differences between assigned scores.

We create another occupational score using information that Preston and Haines (1991) compiled from Commissioner of Labor (1903), Douglas (1930), and Lebergott (1964). This provides estimates of annual income by detailed occupation circa 1900. ${ }^{21}$ Preston and Haines (1991) do not provide an estimate for farmers, and so we used the 1900 Census of Agriculture to estimate average net income for white farmers based on the reported value of farm production, cost of inputs, and estimates of in-kind income. Again, we use this measure to compute a ranking.

Finally, we use the two ranking schemes to create an average occupational rank, which is the simple average of ranks based on the two occupational scores discussed above. This is our preferred

\footnotetext{
${ }^{19}$ In cases where a region-occupation cell has fewer than 100 observations, the score is based on a broad occupational category (e.g., white collar) rather than on the specific occupation.

${ }^{20}$ In the case of ties, we assign individuals the average rank of the occupational group. So, if farmers were 20 percent of the work force and ranged from the 50th to 70th percentile, we would assign them a rank of 0.6. ${ }^{21}$ The Preston and Haines (1991) occupation codes do not correspond directly to those in the current IPUMS files (occ1950). Therefore, we merged the "old" Preston-Haines public use microdata sample (https://usa.ipums.org/usa/samples.shtml), which includes both the Preston-Haines occupation codes and the occ1950 census codes, with the Preston-Haines income data, and then collapsed the data to calculate averages for occ 1950 cells. We thank Laura Salisbury for providing helpful insight on this issue.
} 
measure for making consistent comparisons across the five cohorts that we study.

Two important issues arise in our analysis of occupations. The first concerns the rank of adult men, recorded as farm laborers, who reside in a household that is headed by a farmer who is a relative (usually their father). ${ }^{22}$ We refer to these individuals as farm family members. One approach would assign them the same rank as farm laborers. In our view, this would be inappropriate. Adult men who chose to work on the family farm may have differed from hired laborers in their role and treatment, and they may have been accruing equity in the farm (Atack and Bateman 1987, pp. 44-45). Indeed, adult sons working on their parents' farm arguably revealed a preference for that position over working elsewhere as a hired farm laborer. Our preferred approach is to rank farm family members at the midpoint of farm laborers and farmers, ${ }^{23}$ which acknowledges their higher average status than laborers but does not assign them the full status of farmers. ${ }^{24}$ In our analysis, we consider three potential rankings for such men, ranging from ranking them with farm laborers (a lower bound) to treating them as farmers (an upper bound).

A related issue is that the 1850 census did not make a careful distinction between farmers and farm laborers, whereas the 1870 and later censuses did (e.g., Conk 1978). This issue is pronounced among (mostly native) men who were not household heads but who lived in farmer-headed households. In 1850, such men were typically classified as "farmers," but in subsequent censuses they were commonly classified as "farm laborers." 25 If unaddressed, this would inflate the initial status of men in 1850 because farmers rank above farm laborers. In turn, because this disproportionately affects natives, this would inflate immigrants" "catching up" between 1850 and 1880. To address the issue, we develop a procedure to apply the 1870 census enumeration practices for men in agriculture to the 1850 census records based on observables (details are in Online Appendix E). ${ }^{26}$ This reassignment is probabilistic at the individual level, and so we cannot know whether each individual is classified correctly. But, as discussed above, our interest is primarily in changes in group averages, and this method should capture the average ranking of men in agriculture

\footnotetext{
${ }^{22}$ In 1850, these are a subset of the men who we recategorize. In general, these are cases where the household head's occ 1950 code is 100-199 and the individual's relate code is from 2-11.

${ }^{23}$ That is, we give farm family members the midpoint of the wealth or income scores of farmers and farm laborers and then rank them according to that score.

${ }^{24}$ For comparison, the midpoint approach typically ranks such men a few percentiles below operatives.

${ }^{25}$ Beginning in 1910, a further distinction was made between farm laborers working on the family farm (occ1950 code 830) and other farm laborers (occ1950 code 820). In prior censuses, only the 820 code was used. To maintain comparability, we revert all 830 codes to 820 in the censuses of 1910, 1930, and 1940.

${ }^{26}$ This relates to the discussion of "farmers without farms" (Bogue 1963; Winters 1978; Atack and Bateman 1987, pp. 44-45; Atack 1989), which was focused on heads of household. Atack and Bateman (1987) argue that there was a distinction between such men and farm laborers.
} 
in 1850 in a way that is more comparable to later censuses.

\section{Empirical strategy and summary statistics}

\section{Empirical strategy}

Our initial focus is on immigrants' unconditional assimilation. That is, we ask the simple but fundamental question of whether immigrants' occupational status converged upon that of natives over the 30 years in which we observe each cohort. We consider this question first in terms of distributions of immigrants and natives across broad occupational categories. Then, we consider it on the basis of the detailed occupational rankings. Our analysis adjusts only for differences in age. It is not possible to use information on immigrants' year of arrival in comparisons of various phases of the Age of Migration because the nineteenth-century censuses did not inquire about this. ${ }^{27}$

Our main empirical approach is to estimate regressions of the form

$$
y_{i t}=\beta_{t} F_{i}+g\left(a_{i t}\right)+\varepsilon_{i t}
$$

where $y_{i t}$ is an outcome for individual $i$ in year $t, F_{i}$ is an indicator for foreign birth, and $g\left(a_{i t}\right)$ is a quartic function in individual $i$ 's age in year $t$. We estimate equation (1) separately for the initial and final census years of each of the five linkage spans. The coefficient $\beta_{t}$ represents the difference in the outcome between natives and immigrants in that census year, conditional on age.

We first use equation (1) to describe differences in the distribution of natives and immigrants over the five broad occupational categories. ${ }^{28}$ To summarize the differences, we compute an ageadjusted version of the dissimilarity index of Duncan and Duncan (1955),

$$
D_{t}=\sum_{k} \frac{1}{2}\left|\hat{\beta}_{t k}\right|,
$$

where $\hat{\beta}_{t k}$ is the coefficient from estimating equation (1) with an indicator for holding an occupation in category $k$ as the dependent variable. ${ }^{29}$

We then use equation (1) to describe differences in occupational rankings based on the narrowly defined occupational codes and focusing on the average occupational rank measure. To measure changes between census years for each cohort, we estimate equation (1) twice by seemingly unrelated regression, first using data from the early census year and then using data from the later

\footnotetext{
${ }^{27}$ Later in the paper (section 8), we discuss whether differences in the distribution of time-since-arrival might confound comparisons over time, and we conclude that this is unlikely.

${ }^{28}$ Farm family members are classified with unskilled laborers.

${ }^{29}$ Estimating the five coefficients by seemingly unrelated regression enables us to compute the standard error of $D_{t}$ by the delta method.
} 
census year. Our measure of assimilation is $\beta_{t}-\beta_{t-30} \cdot{ }^{30}$ The difference will be positive in cases where immigrants increased average levels of $y$ relative to natives over time, and indicates assimilation in cases where immigrants were initially behind natives.

Finally, for insight regarding conditional assimilation, we compare immigrants' occupational upgrading to that of natives who start in occupations with similar economic status. We estimate equations of the form

$$
R_{i t}-R_{i t-30}=\delta F_{i}+\gamma R_{i t-30}+g\left(a_{i t-30}\right)+\eta_{i}
$$

where $R_{i t}-R_{i t-30}$ is the change in worker's average rank measure between the two periods, $R_{i t-30}$ is the worker's rank in the initial year based on the detailed occupational coding and scoring described above, and all other notation is the same as in equation (1). The coefficient $\delta$ measures the average upgrading of immigrants relative to natives conditional on the worker's initial occupational status and a quartic in age. This enables us to determine whether changes in unconditional assimilation across cohorts primarily reflected changes in lifetime mobility (as registered in conditional assimilation) or changes in initial occupational distributions.

\section{Summary statistics}

Figure 3 shows the country-of-origin mix within our linked samples. In the samples beginning in 1850, 1870, and 1880, immigrants from Ireland, Germany, and Britain were predominant, though the sharp decline of the Irish share is notable, as is the gradual rise of the Swedish share. After 1880, but especially between 1900 and 1910, the shares increased for Italy, Russia, and the Austro-Hungarian Empire, though the "old" sources continued to make up a substantial fraction of the young immigrant population.

Figure 4 depicts broad occupational distributions for each cohort of natives and immigrants. In each of the five initial census years (left panels), the modal immigrant held an unskilled occupation, and immigrants were more likely than natives to be in such jobs, especially in 1850 and 1910. The modal native worker was a farmer or farm family member in the early cohorts, but both unskilled and white-collar shares tended to rise over time as the manufacturing and service sectors grew.

By each of the final five census years (right panels), both immigrants and natives reduced their share in unskilled occupations over their lifecycle. In the earlier cohorts, both groups shifted

\footnotetext{
${ }^{30}$ We use seemingly unrelated regression because the estimates of immigrant-native differences will be correlated for a linked sample across its two years (i.e., $\varepsilon_{i t}$ and $\varepsilon_{i t-30}$ will be correlated). Seemingly unrelated regression adjusts standard errors for this and enables proper hypothesis testing of $\beta_{t}-\beta_{t-30}$.
} 
strongly into the farmer category. In the later cohorts, white-collar work surpassed farming as the modal end-of-career occupation for natives, whereas immigrants' modal occupation was still unskilled despite sharp declines in that category compared to when they were young men. By the final year of each span, the farm family category had greatly dwindled.

Figure 5 depicts the immigrant-native gap in initial occupational rank. We plot three series, each of which makes a different assumption about how farm family members are ranked. In all cases, immigrants are initially ranked behind natives, with the greatest initial differences in 1850 and in 1910, leading to the graph's inverse-U shape. Because farm family members were predominantly native-born, the gap tends to narrow (the inverse- $U$ shifts up) when farm family members are assigned lower ranks. Under our preferred ranking, which puts farm family members at the midpoint of farmers and farm laborers, the initial gap in occupational status ranges from about 12 percentiles for the first and last cohorts to about 5 percentiles for the intermediate cohorts. Additional summary statistics for each of the linked samples are provided in Online Appendix Table A.1.

\section{Unconditional Labor Market Assimilation over the Age of Mass Migration}

Figure 6 presents the difference in immigrants' and natives' occupational distributions across five broad occupational categories using the dissimilarity index described above. ${ }^{31}$ The solid line presents the value of the index in the initial year of each span, and the dark dashed line presents the value in the final year. The thin dashed lines connect the initial and final year of each span. Mirroring the pattern presented in Figure 5, there is a U-shape in the initial value of the index (dark solid line), with the first and last periods exhibiting the greatest initial occupational segregation and with the middle cohorts exhibiting lower values. For perspective, an index value of, say, 0.23 would imply that 23 percent of immigrants or natives would have to move across occupational categories to equalize the immigrant and native distributions. For all cohorts, there is a decline in the value of the dissimilarity index from the initial year to the final year, indicating a decline in occupational segregation and, from this perspective, labor market assimilation.

It is possible, however, that broad occupational categories obscure important variation within each category; moreover, such broad categories provide a limited sense of whether men are moving up or down the occupational ladder with time. Therefore, we incorporate more detailed occupational definitions into the analysis and, as described above, rank occupations based on what is known about

\footnotetext{
${ }^{31}$ Here, we have grouped farm family workers with the unskilled labor category (which always includes farm laborers). Online Appendix Table A.2 presents these figures and their standard errors. Online Appendix Table A. 3 shows the differences in the occupational category indicators for each year and category.
} 
the average economic status of men holding them. We focus on changes in the average occupational rank and the assimilation measure $\beta_{t}-\beta_{t-30}$.

Figure 7 reports a clear U-shaped pattern in the convergence of immigrants' occupational rank relative to natives' rank, with the greatest such convergence in the first and last cohorts. ${ }^{32}$ Focusing first on measures with our preferred "midpoint rank" for farm family workers, we see in the 1850-1880 cohort that immigrants' average relative gain was about 4 percentiles, relative to a base gap of 12 percentiles (Figure 5), thus closing one-third of the initial gap in status; for the 1910-1940 cohort, immigrants' average relative gain is closer to 6 percentiles, relative to a base gap of 12.5 percentiles. Changing the rank assignment for farm family workers tends to shift the U-shape up (when ranking such men with farmers) or down (when ranking them with farm laborers), as expected. But the U-shape itself and the strong positive upgrades for the 1910-40 cohort are robust.

Relative gains were low for the middle three cohorts, though the initial gaps were also smaller. Among this group, the 1900-1930 cohort is of particular interest because it overlaps with the period studied in Abramitzky, Boustan, and Eriksson (2014), which finds minimal convergence between immigrants and natives. In our analysis, this cohort is at or near the bottom of the $U$ and experienced little or no convergence on natives - consistent with their conclusions.

Overall, did European immigrants' labor market outcomes become more like those of natives as they gained experience in American labor markets during the Age of Mass Migration? In terms of differences in their distribution across broad occupational categories, the answer is a clear "yes" (Figure 6). In terms of occupational rank (Figure 7), the story is more complicated. A key insight is that the pattern of relative gains varied over cohorts. For the $1850-1880$ period, our preferred metric indicates substantial relative gains for immigrants; this diminishes when we assign farm family workers (mostly natives) a rank that we view as a lower bound, and it rises when we rank such men with farmers. For the three next three cohorts, there is little evidence of substantial relative gains, and whether the estimate is slightly positive or negative depends on the rank assigned to farm family workers. For the 1910-1940 cohort, immigrants experienced substantially greater occupational upgrading than natives by any measure. ${ }^{33}$

\footnotetext{
${ }^{32}$ Online Appendix Table A.5, column (1) presents these estimates and their standard errors based on estimating equation (2) without controlling for initial rank. This approach is very similar, though not numerically identical, to using the $\beta_{t}-\beta_{t-30}$. Online Appendix Table A.4 presents the results using various alternative scoring and ranking schemes. The U-shaped convergence pattern is robust to the choice of scoring or ranking method.

${ }^{33}$ The standard errors of all of these estimates are very small, ranging from about 0.001 to 0.003 .
} 


\section{Conditional gains in occupational status}

The changing pattern of unconditional rank-based assimilation over the Age of Mass Migration could primarily reflect changes in natives' or immigrants' occupational mobility or, alternatively, changes in their initial distributions of occupations, each of which had a different likelihood of leading to upward mobility. To better understand the empirical underpinnings of the unconditional results, we start by estimating equation (2), which measures the average difference in upgrading between immigrants and natives conditional on their initial occupational status (and age).

Figure 8 reports the results, again with low, middle, and high rank assignments for farm family workers. ${ }^{34}$ First, we see that immigrants in every cohort upgraded less than natives who were comparably positioned in the base year. This runs contrary to the notion that immigrants were initially under-placed in the labor market relative to their underlying skills or productivity but erased that disadvantage with the accumulation of experience in the United States. Second, there was a notable change in immigrants' conditional assimilation. In the 1850-1880 linked sample, immigrants' average occupational upgrade was 5 to 6 percentiles less than that of natives with a similar initial position. Immigrants fared somewhat better in terms of conditional assimilation in subsequent cohorts, but still trailed natives by about 2 to 3 percentiles. ${ }^{35}$

Figure 9 provides a more disaggregated view. We group men by broad categories for their initial-year job, and then we calculate average changes in status using the underlying detailed occupational information. These changes are expressed relative to the average upgrade for natives who initially held white-collar occupations (the horizontal line at zero). For this and subsequent figures, we set the rank of farm family members to the midpoint between that of farm laborers and farmers. ${ }^{36}$ Two patterns stand out. First, average upgrading from the "unskilled" category is considerably larger than from any other category - this is true for every cohort. Second, immigrants experienced less occupational upgrading than natives in almost every case. This is especially noticeable in the 1850-1880 cohort, consistent with the results of Figure 8.

It is remarkable that the $1850-1880$ cohort of immigrants experienced substantial unconditional convergence on natives despite a relatively poor record of conditional convergence. Our earlier discussion of differences in initial occupational distributions (Figure 4) combined with the upgrading patterns revealed in Figure 9 clarify the source of this cohort's relative gains. In 1850,

\footnotetext{
${ }^{34}$ Full estimates are presented in Online Appendix Table A.5, column (2).

${ }^{35}$ The standard errors of these estimates are small, ranging from about 0.001 to 0.002 .

${ }^{36}$ Online Appendix Figures A.1 and A.2 present analogous figures ranking farm family members at the level of farmers or farm laborers.
} 
immigrants were heavily over-represented relative to natives in unskilled labor, from which subsequent upgrading was relatively high (for both immigrants and natives); they were underrepresented relative to natives in farming, from which subsequent upgrading was low. ${ }^{37}$

In subsequent cohorts of young men (starting in 1870, 1880, and 1900), immigrants' overrepresentation in unskilled labor declined, as did natives' initial concentration in farming - the groups became more similar. These changes tended to diminish immigrants' overall upgrading relative to natives, despite some modest improvement in their conditional upgrading compared to the 1850-1880 cohort (Figure 8). Finally, in 1910, we again see a substantial over-representation of immigrants in unskilled labor, reminiscent of 1850, whereas natives remained over-represented in farming and became strongly over-represented in white-collar occupations. Once again, the compositional differences in initial occupations underpinned immigrants' overall gains relative to natives' occupational status, despite their persistent disadvantage in terms of conditional assimilation.

Altogether, these results imply that the changes in immigrants' rank-based assimilation over the Age of Mass Migration were not driven by changes in immigrants' performance relative to initially similar natives. Instead, changes in immigrants' and natives' occupational distributions were key. Figure 10 illustrates this argument more concretely. A group's average upgrading can be decomposed into the distribution of men across initial occupations and the average gains in status conditional on the distribution across occupations. If changes in initial occupational distributions are key to generating the U-shape of assimilation across cohorts (and changes in conditional assimilation are not), then we should be able to generate a counterfactual U-shape by letting the initial occupational distribution change from cohort to cohort, even if conditional assimilation patterns are fixed (i.e., not allowed to change over cohorts). ${ }^{38}$ This is precisely what Figure 10 showsregardless of which cohort's conditional upgrading pattern we select as the "fixed" component, the changes in initial occupations trace out pronounced counterfactual U-shapes that are generally similar to the "true" U-shape. ${ }^{39}$ The 1850-based line is noticeably lower than the others because this cohort had weaker conditional upgrading (Figure 8), but it still traces out a U-shape.

Figure 11 instead fixes the initial occupational distribution and allows only the conditional

\footnotetext{
${ }^{37}$ In section 8 , we investigate whether allowing within-occupation changes in economic status, based on agewealth profiles, changes this interpretation. It does not.

${ }^{38}$ To implement this, we start with a specific linked sample (with its inherent conditional upgrading patterns), and then we reweight the sample repeatedly to have the same initial occupational distribution as in every other cohort. Figure 10 then plots five series, based on estimating equation (2) without controlling for initial rank, where each series is based on a different cohort's conditional upgrading patterns and where each point within a series reflects a different initial occupational mix. We also plot the "true" upgrading series for reference.

${ }^{39}$ Online Appendix Figures A.3 and A.4 present analogous figures for alternate ranks of farm family members.
} 
upgrading pattern to change from cohort to cohort. ${ }^{40}$ Changes in conditional upgrading patterns cannot generate a counterfactual U-shape. Instead, the most pronounced feature is that the 1850- and 1910-based occupational mixes imply high rates of counterfactual assimilation regardless of which cohort's conditional upgrading pattern that is applied, again confirming the empirical importance of the young men's occupational mix.

\section{The (small) role of changing source countries}

There are, of course, potential interpretations of the U-shaped trend in assimilation that emphasize changes other than those in the initial occupational distribution. For instance, influential commentators and policymakers in the early twentieth century lamented the arrival of "new" immigrants and questioned their ability to adapt to life in the United States. This view framed the "immigration problem" that the literacy test and then the quota system were intended to solve. But at the time (and until now) data did not exist to study the issue carefully.

The validity of this view is immediately called into question by the assimilation of the 19101940 cohort of immigrants, who were drawn largely from "new" sources. Nonetheless, the broader point, that changes in the distribution of country-of-origin may have influenced assimilation patterns across cohorts, remains possible.

What would immigrants' assimilation patterns have looked like had there not been a change in immigrants' source countries? We can use reweighting methods, similar to those described above, to address this question. Instead of holding constant the initial distribution of occupations within each series, we hold constant the distribution of nationalities, allowing the actual occupational distribution (within each nationality) and upgrading patterns to prevail. For instance, we can estimate a counterfactual assimilation trend in which the distribution of nationalities remains fixed at 1850 levels (i.e., largely British, German, and Irish) while unconditional upgrading patterns for each country-of-origin group change over time as they actually did.

Figure 12 plots counterfactual trends based on 1850-, 1870-, and 1880-based immigrant populations, which are dominated by the "old source" countries of North and West Europe, along with the "true" assimilation curve for reference. ${ }^{41}$ If immigrants from "old source" countries were

\footnotetext{
${ }^{40}$ In Figure 11, each plotted series is based on a different cohort's (fixed) initial occupational mix and each point within a series reflects a different cohort's upgrading pattern.

${ }^{41}$ Online Appendix Figure A.5 presents analogous figures for alternative rankings of farm family members. We exclude the curves based on the 1900 and 1910 nationality distributions because they are not particularly informative - there were too few immigrants from the "new" source countries in the United States prior to 1900 to make these curves useful to consider.
} 
consistently more successful in upgrading than others, we would expect high rates of counterfactual upgrading compared to actual upgrading across the cohorts. The results effectively rule out changing immigrant source countries as an important explanation for the changing patterns in assimilation across cohorts. Regardless of which cohort's country-of-origin distribution is selected-each of which heavily weights "old" source immigrants - a similar U-shaped pattern of assimilation arises. The precise magnitude of the changes over time are affected by the weighting; for instance, the 1850 nationality mix would have been associated with the worst relative upgrading. But the fundamental pattern clearly does not hinge on having a changing mix of immigrant source countries that shifts toward Southern and Eastern Europe. ${ }^{42}$

\section{Robustness}

In the Online Appendix, we rule out several concerns regarding the robustness of the results. As mentioned above, due to the lack of time-of-arrival information in 1940 and the consequent necessity to weight the linked sample to match the 1910 population at risk for linkage, selective return migration between 1910 and 1940 could bias estimates of assimilation for that cohort. In Online Appendix F, we create 20-year linked samples, including a 1910-1930 sample (i.e., like the 1910-1940 sample, one that captures immigrants in the United States by 1910), where our weighting can effectively address this issue. The results show that even when ranking farm family members as equivalent to farm laborers, we can bound the assimilation of this cohort below at zero and our preferred estimate, based on the midpoint ranking of farm family members, is substantially positive. Moreover, we still observe an upswing in rank-based assimilation for the 1910 cohort relative to earlier groups.

More generally, it is possible that changing patterns of selective return migration might have been responsible for the changing patterns of occupational upgrading (Online Appendix G). ${ }^{43} \mathrm{We}$ can address this concern by reweighting the 1870-1900, 1880-1910, and 1900-1930 samples to match the distribution of men's observables in the first year of the linkage span. The initial census in each span includes eventual returners. In practice, this approach upweights immigrants in unskilled jobs with higher upgrading potential, and we can see whether this translates into substantially higher

\footnotetext{
${ }^{42}$ Online Appendix Figure A.6 presents occupational upgrading figures by initial occupation and nationality. This figure is analogous to Figure 9 but divides immigrants by country of origin.

${ }^{43}$ For instance, the greatest upgraders in the earliest cohort may have stayed in the United States whereas those in the intermediate cohorts, where return migration was higher, may have returned.
} 
average upgrading, assuming leavers would have upgraded as much as stayers. ${ }^{44}$ We find that this explanation cannot account for the changes in labor market assimilation observed.

Another concern is the continued assimilation of second-generation immigrants (Abramitzky et al. 2021b), which would be of particular relevance in the later periods. That is, the inclusion of immigrants' children who were born in the United States in the "natives" category might lead to an understatement of immigrants' relative gains. Online Appendix H repeats our main results comparing immigrants to natives who had native fathers. Our results are qualitatively unchanged.

It is also possible that some immigrants in our samples had been in the United States for a long time before our "initial" measurement of their status and, perhaps, had already experienced a period of rapid assimilation. We can use the information on each immigrant's year of arrival to limit the sample to those who arrived within 10 years of the initial census. ${ }^{45}$ Again, our results, shown in Online Appendix I, are qualitatively unchanged.

We also develop two alternative occupational wealth scores, both based on the full count 1870 census records. The first is designed to allow changes in scores over the lifecycle even for men who do not change occupations. Specifically, we derive scores that are based on the wealth holdings of younger (18-30) and older (34-64) men within each detailed occupational category. If, for example, the age-wealth profile were steeper among farmers than other occupational categories, this approach would allow that fact to register in the assignment of scores. The second alternate wealth score allows for variation across states. Results with these alternate scores, presented in Online Appendix $\mathrm{J}$, are qualitatively identical to those that we present in the main text.

Ward (2021) points out that there may be errors in the recording of occupations. If such errors are random, they should not greatly impact measures of groups' average status. However, such errors may be dangerous if men who did not speak English had difficulty communicating their occupations to census enumerators and, therefore, tended to be categorized as common laborers. In Online Appendix K, we repeat the main analysis while excluding men who ever reported being unable to speak English (a question asked only from 1900 to 1930). This requires the exclusion of much of the bottom tail of the immigrant occupational distribution, especially in 1910-1940, but the main results are qualitatively robust.

Finally, it is possible that the U-shape in assimilation was driven by a decline and subsequent rise in immigrant selection (i.e., the intermediate, low upgrading cohorts had lower unobservable

\footnotetext{
${ }^{44}$ We view this as an upper bound based on Abramitzky, Boustan, and Eriksson (2019).

${ }^{45}$ We cannot do this for the $1850-1880$ sample, but the concern is less likely to apply for that cohort because immigration rates were much higher after 1840 than before.
} 
quality and thus a lesser tendency to upgrade). But more negative selection in the intermediate cohorts could have affected their observed upgrading in two ways. First, their upgrading from specific occupations could be weaker. This is inconsistent with our findings that changes in conditional upgrading were not important drivers of the U-shaped assimilation pattern and that the intermediate cohorts fared at least as well as the others in conditional upgrading. ${ }^{46}$ Second, more negative selection could have increased their initial concentration in unskilled labor. But if so, this would tend to place immigrants in occupations from which workers experienced greater upgrading. We would expect more, not less, upgrading in the middle cohorts if this mechanism were important.

\section{Discussion}

Taken together, the results of sections 5, 6, and 7 indicate that prevalent views of European immigrants' labor market assimilation during the Age of Mass Migration are incomplete and require revision. Rather than a uniform phenomenon in which European immigrants started behind and then "worked their way up" the occupational ladder relative to natives, we showed in section 5 that immigrants' rank-based assimilation followed a U-shaped trend, with the first and last major cohorts of the Age of Mass Migration experiencing substantial convergence relative to natives, unlike the intervening cohorts. But while the "catching up" of the first and last cohorts of immigrants was real and contrasts with the experiences of the intervening cohorts, it was clearly not the product of immigrants' superior performance relative to comparably placed natives, nor was it the product of changing immigrant source countries. Rather, as we showed in section 6, young immigrants in these cohorts were disproportionately concentrated in jobs from which many workers were likely to upgrade during their lifetime, whether native or immigrant, new source or old. Conversely, young natives in these cohorts were over-represented in jobs from which upgrading was comparatively low.

Although it might be tempting to suppose that immigrants' concentration toward the bottom of the occupational ladder made upward mobility the only possibility, the findings are not the result of processes that are mechanical or inevitable. The experience of Black Americans since the Civil War shows that upward mobility from the bottom of the occupational distribution can be very slow (Collins and Wanamaker 2021). The combination of falling initial status and slowing assimilation for immigrant cohorts in more recent decades also stands in contrast to immigrants' experience in the

\footnotetext{
${ }^{46}$ A related question is whether Black migration from the South altered the trajectory of immigrants' assimilation for the last cohorts in our analysis. We find that omitting the cities with the largest inflows of Black migrants (Chicago, Philadelphia, New York, Detroit, and St. Louis) has little effect on our results. These results are available on request.
} 
Age of Mass Migration.

Identifying the deep determinants of changes in young men's early career occupations during the Age of Mass Migration is beyond the scope of this paper. But these changes can be interpreted in the context of secular forces acting on the American economy and particular episodes in the history of European migration. First, the structural transformation of the economy contributed to the decline in young natives' agricultural employment, the rise of nonfarm unskilled work, and eventually the rise of white-collar occupations. Three properties of modern economic growth underpinned this change: the low income elasticity of demand for farm products; relatively rapid productivity growth in agriculture; and the declining cost of acquiring education with the extension of public schooling (inter alia, Clark 1940; Lewis 1964; Kuznets 1966; Caselli and Coleman 2001). Even if it was difficult and unlikely for a given farmer to switch to non-farm employment in mid-career, these secular forces ensured that each new generation of workers faced a different opportunity set, and many responded by pursuing jobs outside of agriculture.

Reinforcing this trend, technological changes in the late nineteenth century led to increased capital-skill complementarity. This tended to reallocate workers to white-collar occupations (Lafortune, Lewis, and Tessada 2019), where we see growing concentrations of young natives by 1910. In addition, Foged and Peri (2016) and Tabellini (2020) have shown that immigrants may be complementary factors of production for natives. Such complementarities may have been especially strong in the latter part of the Age of Mass Migration when most natives resided in urban areas which received large inflows of immigrants, many of whom had limited English skills. Thus, it is plausible that natives' increasing concentration in white-collar occupations reflected, in part, a response to the large influx of less-skilled and more complementary immigrants.

The concentration of immigrants in unskilled occupations in the first and last cohorts is also notable and empirically important. For these cohorts, the sheer volume of immigrant inflows prior to the span's initial census year stands out. In the 1840s, this surge was primarily the product of Irish fleeing the Great Famine and Germans migrating in the wake of political upheaval (Cohn 2009). The causes of the surge in immigration around 1900 remain the subject of debate, but key explanations include the increasing modernization of the European periphery (Thistlethwaite 1960; Hatton and Williamson 1998) and the spread of European migrant networks (Gould 1980; Spitzer and Zimran 2021). Regardless of the cause, these particularly large inflows may have strained labor markets' absorptive capacity and the ability of pre-existing migrant networks to assist in the occupational placement of new arrivals (Beaman 2012). In these cohorts, large shares of young immigrants started their careers in the common laborer category, but as we have seen, many substantially upgraded their 
occupational status over their lifetime.

\section{Conclusions}

Recent advances in data availability have enabled scholars to revisit fundamental questions about the first era of mass immigration to the United States. One of those questions pertains to immigrants' labor market outcomes, specifically whether immigrants improved their economic status relative to natives as they gained experience in the labor market. In this paper, we provide a more complete view of the Age of Mass Migration, providing consistent comparisons of immigrants who arrived at different times and from different sources, and delving into the factors driving changes in assimilation patterns over time.

From a contemporary perspective, at a time when immigration policy is again at the forefront of political discourse, this paper's investigation is valuable because many Americans have strongly held views about the experiences of European immigrants in the Age of Mass Migration and what those experiences imply about appropriate policy today (Smith et al. 2018; Martin 2019). Anecdotes, family lore, and wishful thinking have tended to predominate over systematic evidence in forming and sustaining those views of American history. We develop new data and analyses that illuminate the Age of Mass Migration and confront the idealized notion that European immigrants simply "worked their way up" the economic ladder.

Our analysis arrives at two main conclusions, each with important implications for understanding the long history of immigration in the United States. The first is that the earliest and last cohorts of European immigrants in the Age of Mass Migration initially trailed natives in occupational status and substantially upgraded their occupational status relative to natives over their lifetime. Other cohorts had an initial occupational status closer to that of natives and experienced smaller relative gains. The second conclusion is that differences in immigrants' upgrading among the early, middle, and later cohorts of the Age of Mass Migration were not rooted in the changing composition of immigrant source countries, which was widely remarked upon and lamented by social scientists and policymakers at the time. Rather, we show that the answer lies in the collapsing and then resurging differences in occupational distributions between young immigrants and natives. We interpret this as a reflection of the structural transformation of the American economy and its interaction with waves of mass immigration. Thus, the first and last cohorts" "catching up" to natives was due largely to the timing of their arrival and the prevailing economic environment, not to advantages associated with their home countries nor to their exceptional personal characteristics. 


\section{References}

Abramitzky, Ran and Leah Platt Boustan (2017). "Immigration in American Economic History." Journal of Economic Literature 55:4, pp. 1311-1345.

Abramitzky, Ran, Leah Platt Boustan, and Katherine Eriksson (2014). "A Nation of Immigrants: Assimilation and Economic Outcomes in the Age of Mass Migration." Journal of Political Economy 122:3, pp. 467-506.

Abramitzky, Ran, Leah Platt Boustan, and Katherine Eriksson (2019). "To the New World and Back Again: Return Migrants in the Age of Mass Migration." Industrial and Labor Relations Review 72:2, pp. 300-322.

Abramitzky, Ran, Leah Platt Boustan, Katherine Eriksson, James J. Feigenbaum, and Santiago Pérez (2021a). "Automated Linking of Historical Data." Journal of Economic Literature 59:3, pp. 865-918.

Abramitzky, Ran, Leah Platt Boustan, Elisa Jácome, and Santiago Pérez (2021b). "Intergenerational Mobility of Immigrants in the US over Two Centuries." American Economic Review 111:2, pp. 580608.

Ager, Philipp, Leah Platt Boustan, and Katherine Eriksson (2021). "The Intergenerational Effects of a Large Wealth Shock: White Southerners After the Civil War." American Economic Review 111:11, pp. 3767-3794.

Alsan, Marcella, Katherine Eriksson, and Gregory Niemesh (2020). "Understanding the Success of the Know-Nothing Party.” NBER Working Paper 28078.

Anbinder, Tyler (1992). Nativism and Slavery: The Northern Know Nothings and the Politics of the 1850s. New York: Oxford University Press.

Atack, Jeremy and Fred Bateman (1987). To Their Own Soil: Agriculture in the Antebellum North. Ames: Iowa State University Press.

Atack, Jeremy (1989). "The Agricultural Ladder Revisited: A New Look at an Old Question with Some Data for 1860." Agricultural History 63:1, pp. 1-25.

Bailey, Martha, Connor Cole, Morgan Henderson, and Catherine Massey (2020). "How Well Do Automated Methods Perform in Historical Samples? Evidence from New Ground Truth." Journal of Economic Literature 58:4, pp. 997-1044.

Bandiera, Oriana, Imran Rasul, and Martina Viarengo (2013). "The Making of Modern America: Migratory Flows in the Age of Mass Migration." Journal of Development Economics 102, pp. 23-47.

Bansak, Cynthia, Nicole Simpson, and Madeline Zavodny (2020). The Economics of Immigration, $2^{\text {nd }}$ ed. New York: Routledge.

Barde, Robert, Susan B. Carter, and Richard Sutch (2006). "Table Ad106-120: Immigrants, by country of last residence-Europe, 1820-1997." In Historical Statistics of the United States. Susan B. Carter, Scott Sigmund Gardner, Michael R. Haines, Alan L. Olmstead, Richard Sutch, and Gavin Wright (eds.). Cambridge: Cambridge University Press, pp. 1.560-1.563.

Beaman, Lori A. (2012). "Social Networks and the Dynamics of Labour Market Outcomes: Evidence from Refugees Resettled in the US.” Review of Economic Studies 79:1, pp. 128-161.

Benton-Cohen, Katherine (2018). Inventing the Immigration Problem: The Dillingham Commission and Its Legacy. Cambridge: Harvard University Press. 
Blau, Francine (1980). "Immigration and Labor Earnings in Early Twentieth Century America." Research in Population Economics 2, pp. 21-41.

Bogue, Allan G. (1963). From Prairie to Corn Belt: Farming on the Illinois and Iowa Prairies in the Nineteenth Century. Chicago: University of Chicago Press.

Borjas, George J. (1985). "Assimilation, Changes in Cohort Quality, and the Earnings of Immigrants." Journal of Labor Economics 3:4, pp. 463-489.

Borjas, George J. (2014). Immigration Economics. Cambridge: Harvard University Press.

Borjas, George J. (2015). "The Slowdown in the Economic Assimilation of Immigrants: Aging and Cohort Effects Revisited Again.” Journal of Human Capital 9:4, pp. 483-517.

Card, David (2005). "Is the New Immigration Really So Bad?” Economic Journal 115, pp. F300F323.

Caselli, Francesco and Wilbur John Coleman II (2001). "The US Structural Transformation and Regional Convergence: A Reinterpretation.” Journal of Political Economy 109:3, pp. 584-616.

Cassidy, Hugh (2019). "Occupational Attainment of Natives and Immigrants: A Cross-Cohort Analysis." Journal of Human Capital, 13:3, pp. 375-409.

Chiswick, Barry R. (1978). "The Effect of Americanization on the Earnings of Foreign-born Men." Journal of Political Economy 86:5, pp. 897-921.

Clark, Colin. (1940). The Conditions of Economic Progress. London: Macmillan.

Cohn, Raymond L. (2009). Mass Migration Under Sail: European Immigration to the Antebellum United States. Cambridge: Cambridge University Press.

Collins, William J. and Marianne H. Wanamaker (2021). "African American Intergenerational Mobility since 1880.” American Economic Journal: Applied Economics, Forthcoming.

Collins, William J. and Ariell Zimran (2019). "The Economic Assimilation of Irish Famine Migrants to the United States." Explorations in Economic History 74, 101302.

Commissioner-General of Immigration (1903). Annual Report of the Commissioner-General of Immigration for the Fiscal Year Ended June 30, 1903. Washington: Government Printing Office.

Commissioner of Labor (1903). Eighteenth Annual Report of the Commissioner of Labor. Washington: Government Printing Office.

Conk, Margo Anderson (1978). "Occupational Classification in the United States Census: 18701940.” Journal of Interdisciplinary History 9:1, pp. 111-130.

Craig, Jacqueline, Katherine Eriksson, and Gregory T. Niemesh (2019). "Marriage and the Intergenerational Mobility of Women: Evidence from Marriage Certificates 1950-1910.” Mimeo., Miami University.

Douglas, Paul H. (1919). "Is the New Immigration More Unskilled than the Old?" Publications of the American Statistical Association 16, pp. 393-403.

Douglas, Paul H. (1930). Real Wages in the United States, 1890-1926. Boston: Houghton Mifflin.

Duncan, Brian and Stephen J. Trejo (2012). "The Employment of Low-Skilled Immigrant Men in the United States.” American Economic Review: Papers and Proceedings 102:3, pp. 549-554.

Duncan, Otis Dudley and Beverly Duncan (1955). "A Methodological Analysis of Segregation 
Indexes.” American Sociological Review 20:2, pp. 210-217.

Eichengreen, Barry and Henry A. Gemery (1986). "The Earnings of Skilled and Unskilled Immigrants at the End of the Nineteenth Century." Journal of Economic History 46:2, pp. 441-454.

Ferrie, Joseph P. (1996). "A New Sample of Males Linked from the Public Use Microdata Sample of the 1850 US Federal Census of Population to the 1860 US Federal Census Manuscript Schedules." Historical Methods 29:4, pp. 141-156.

Ferrie, Joseph P. (1999). Yankeys Now: Immigrants in the Antebellum United States, 1840-1860. New York: Oxford University Press.

Fisher, Irving (1921). "Impending Problems of Eugenics." Scientific Monthly XIII (September): 214-231.

Foged, Mette and Giovanni Peri (2016). "Immigrants' Effect on Native Workers: New Analysis on Longitudinal Data." American Economic Journal: Applied Economics. 8:2, pp. 1-34.

Goldin, Claudia (1994). "The Political Economy of Immigration Restriction in the United States, 1890 to 1921." In The Regulated Economy: A Historical Approach to Political Economy. Claudia Goldin and Gary D. Libecap (eds.). Chicago: University of Chicago Press, pp. 223-258.

Gould, John D. (1980). “European Inter-continental Emigration: The Role of 'Diffusion' and 'Feedback.'” Journal of European Economic History 9:2, pp. 267-315.

Haines, Michael R. and Richard Sutch (2006). "Table Aa6-8: Population: 1790-2000 [Annual Estimates]." In Historical Statistics of the United States. Susan B. Carter, Scott Sigmund Gardner, Michael R. Haines, Alan L. Olmstead, Richard Sutch, and Gavin Wright (eds.). Cambridge: Cambridge University Press, pp. 1.28-1.30.

Hanes, Christopher (1996). "Immigrants' Relative Rate of Wage Growth in the Late 19th Century." Explorations in Economic History 33, pp. 35-64.

Hannon, Joan U. (1982). "Ethnic Discrimination in a Nineteenth Century Mining District: Michigan Copper Mines 1888." Explorations in Economic History 19, pp. 28-50.

Hatton, Timothy J. (1997). "The Immigrant Assimilation Puzzle in Late Nineteenth-Century America." Journal of Economic History 57:1, pp. 34-62.

Hatton, Timothy J. (2000). "How Much Did Immigrant 'Quality' Decline in late Nineteenth Century America?” Journal of Population Economics 13, pp. 509-525.

Hatton, Timothy J. and Zachary Ward (2019). "International Migration in the Atlantic Economy 1880-1940." In Handbook of Cliometrics. Claude Diebolt and Michael Haupert (eds.). Springer.

Hatton, Timothy J. and Jeffrey G. Williamson (1998). The Age of Mass Migration: Causes and Economic Impact. New York: Oxford University Press.

Higham, John (1955). Strangers in the Land: Patterns of American Nativism, 1860-1925. New Brunswick: Rutgers University Press.

Hourwich, Isaac (1912). Immigration and Labor: The Economic Aspects of European Immigration to the United States. New York: G.P. Putnam and Sons.

Hutchinson, E.P. (1981). Legislative History of American Immigration Policy 1798-1965. Philadelphia: University of Pennsylvania Press.

Jenks, Jeremiah W. and W. Jett Lauck (1912). The Immigration Problem. New York: Funk \& 
Wagnalls.

Kelly, John (2018). "Transcript: White House Chief of Staff John Kelly's Interview with NPR" [Interview]. NPR.org. URL: https://www.npr.org/2018/05/11/610116389/transcript-white-housechief-of-staff-john-kellys-interview-with-npr. Accessed September 20, 2019.

Kennedy, John F. (1964). A Nation of Immigrants: Revised and Enlarged Version. New York: Harper \& Row.

Kuznets, Simon (1966). Modern Economic Growth: Rate, Structure, and Spread. New Haven: Yale University Press.

Lafortune, Jeanne, Ethan Lewis, and José Tessada (2019). "People and Machines: A Look at the Evolving Relationship between Capital and Skill in Manufacturing, 1860-1930, Using Immigration Shocks." Review of Economics and Statistics 101:1, pp. 30-43.

Lebergott, Stanley (1964). Manpower in Economic Growth: The American Record since 1800. New York: McGraw-Hill.

Lewis, William A. (1964). "Economic Development with Unlimited Supplies of Labour." Manchester School 22:2, pp. 139-191.

Lubotsky, Darren (2007). "Chutes or Ladders? A Longitudinal Analysis of Immigrant Earnings." Journal of Political Economy 115:5, pp. 820-867.

Lubotsky, Darren (2011). "The Effect of Changes in the US Wage Structure on Recent Immigrants' Earnings." Review of Economics and Statistics 93:1, pp. 59-71.

Martin, Rachel (2019). "Rule Would Penalize Immigrants to US for Needing Benefits" [Interview]. NPR.org. URL: https:/www.npr.org/2019/08/13/750727515/rule-would-penalize-immigrants-to-u-sfor-needing-benefits. Accessed September 20, 2019.

Minns, Chris (2000). "Income, Cohort Effects, and Occupational Mobility: A New Look at Immigration to the United States at the Turn of the 20th Century." Explorations in Economic History 37, pp. 326-350.

Pérez, Santiago (2021). "Southern (American) Hospitality: Italians in Argentina and the US during the Age of Mass Migration.” Economic Journal 131, pp. 2613-2628.

Peri, Giovanni and Zachariah Rutledge (2021). "Economic Assimilation of Mexicans and Central Americans in the United States." IZA Journal of Development and Migration Forthcoming.

Preston, Samuel H. and Michael R. Haines (1991). Fatal Years: Child Mortality in Late Nineteenth Century America. Princeton: Princeton University Press.

Ruggles, Steven, Sarah Flood, Ronald Goeken, Josiah Grover, Erin Meyer, Jose Pacas, and Matthew Sobek (2020). IPUMS USA: Version 10.0 [Machine-readable database]. Minneapolis: University of Minnesota.

Smith, Tom W., Michael Davern, Jeremy Freese, and Stephen Morgan (2018). General Social Surveys, 1972-2018 [Machine-readable data file]. Chicago: NORC.

Spitzer, Yannay and Ariell Zimran (2021). "Like an Ink Blot on Paper: Testing the Diffusion Hypothesis of Mass Migration, Italy 1876-1920.” Mimeo., Vanderbilt University.

Tabellini, Marco (2020). "Gifts of the Immigrants, Woes of the Natives: Lessons from the Age of Mass Migration.” Review of Economic Studies 87, pp. 454-486. 
Thistlethwaite, Frank (1960). "Migration from Europe Overseas in the Nineteenth and Twentieth Centuries." In A Century of European Migrations, 1830-1930. R. J. Vecoli and S. M. Sinke (eds.). Urbana: University of Illinois Pres, pp. 17-57.

US Congress (1911). Reports of the Immigration Commission, vol. 1. Washington: Government Printing Office, $61^{\text {st }}$ Congress, $3^{\text {rd }}$ Session, Document No. 747.

Villarreal, Andrés and Christopher R. Tamborini (2018). "Immigrants' Economic Assimilation." American Sociological Review 83:4, pp. 686-715.

Walker, Francis A. (1896). "Restriction of Immigration.” Atlantic June 1896.

Ward, Zachary (2020). "The Not-So-Hot Melting Pot: The Persistence of Outcomes for Descendants of the Age of Mass Migration." American Economic Journal: Applied Economics 12:4, pp. 73-102.

Ward, Zachary (2021). "Intergenerational Mobility in American History: Accounting for Race and Measurement Error.” NBER Working Paper 29256.

Willcox, Walter F. (1906). "The Distribution of Immigrants in the United States." Quarterly Journal of Economics 20:4, pp. 523-546.

Williamson, Jeffrey G. (1998). "Labor Markets and Policy Backlash in the Past." Journal of Economic Perspectives 12, pp. 51-72.

Winters, Donald L. (1978). Farmers without Farms: Agricultural Tenancy in Nineteenth-Century Iowa. Westport: Greenwood Press.

Zimran, Ariell (2021). "Immigrant Distribution in the United States during the Age of Mass Migration.” NBER Working Paper 28812.

Zolberg, Aristide R. (2006). A Nation by Design: Immigration Policy in the Fashioning of America. Cambridge: Harvard University Press. 


\section{Figures}

Figure 1: European Annual Immigration Rate as a share of US population

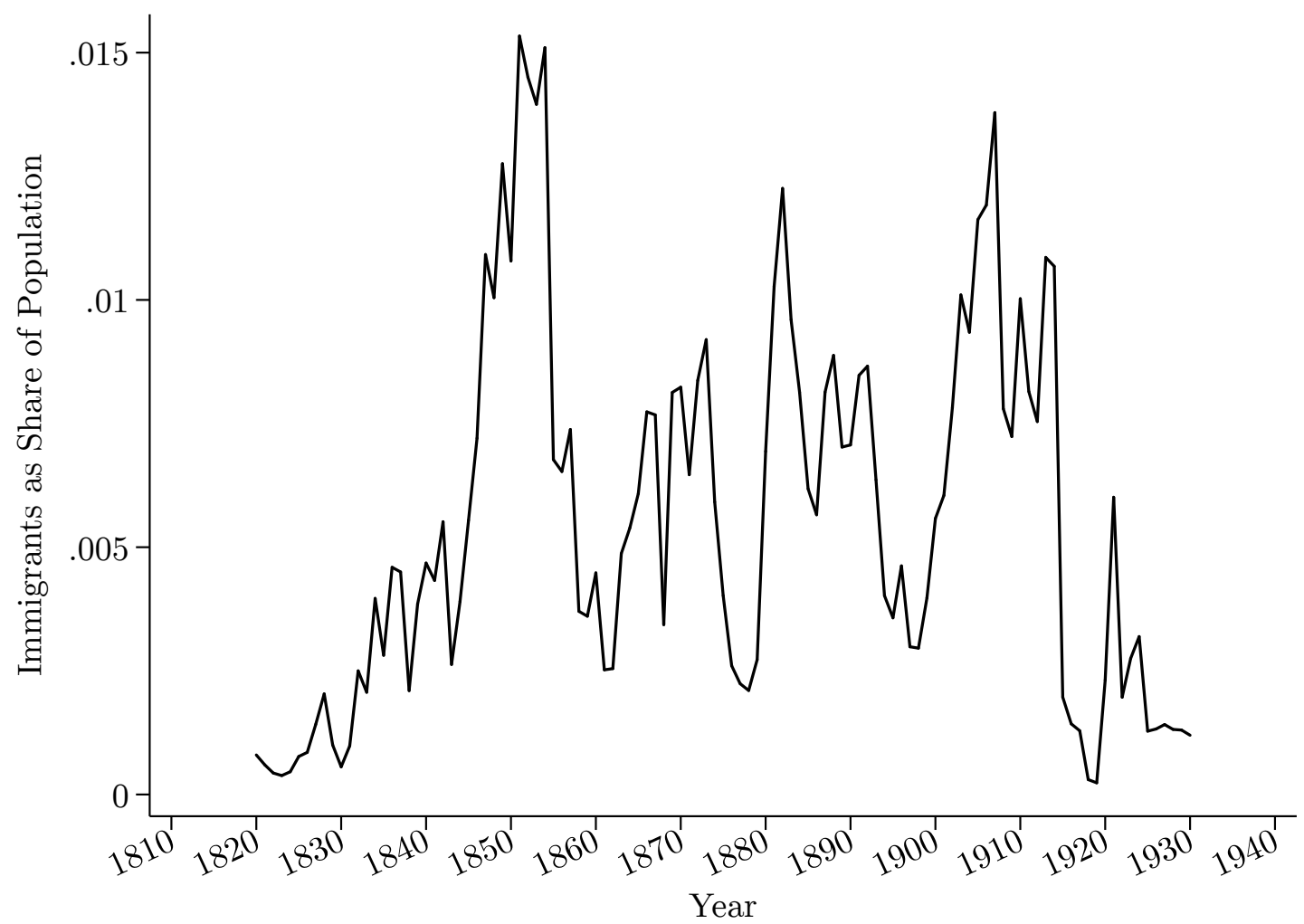

Notes: Population counts are from Haines and Sutch (2006). Immigration counts are from Barde, Carter, and Sutch (2006). 
Figure 2: Immigrant and native occupation shares

Figure 2(a): Natives

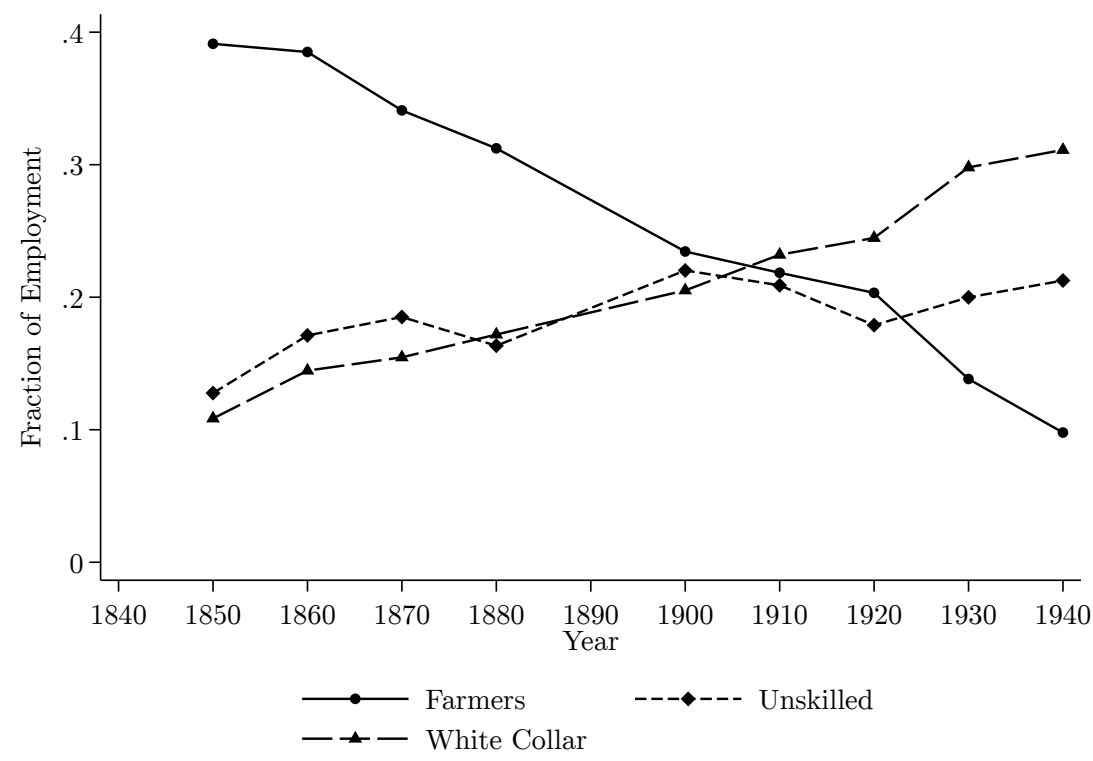

Figure 2(b): Immigrants

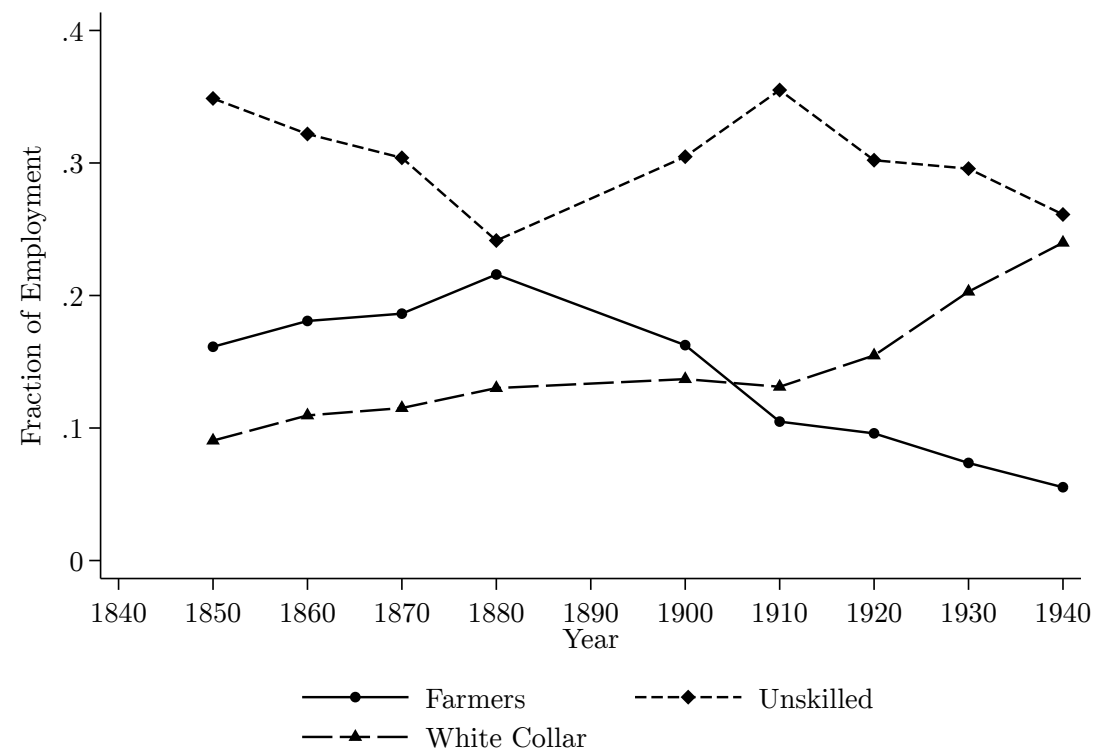

Notes: Data are from 100\% samples of the 1850-1940 censuses (excluding 1890) provided by Ruggles et al. (2020). Occupations defined as in footnote 20. Unskilled occupations exclude farm family members (i.e., farm laborers living in a household headed by a farmer to whom they are related). Occupations in 1850 are corrected for the changing definition of farm laborer, as described in section 3. Immigrants restricted to those from European countries. Both natives and immigrants limited to white males ages 18-65. 
Figure 3: Country-of-origin distributions of our linked samples

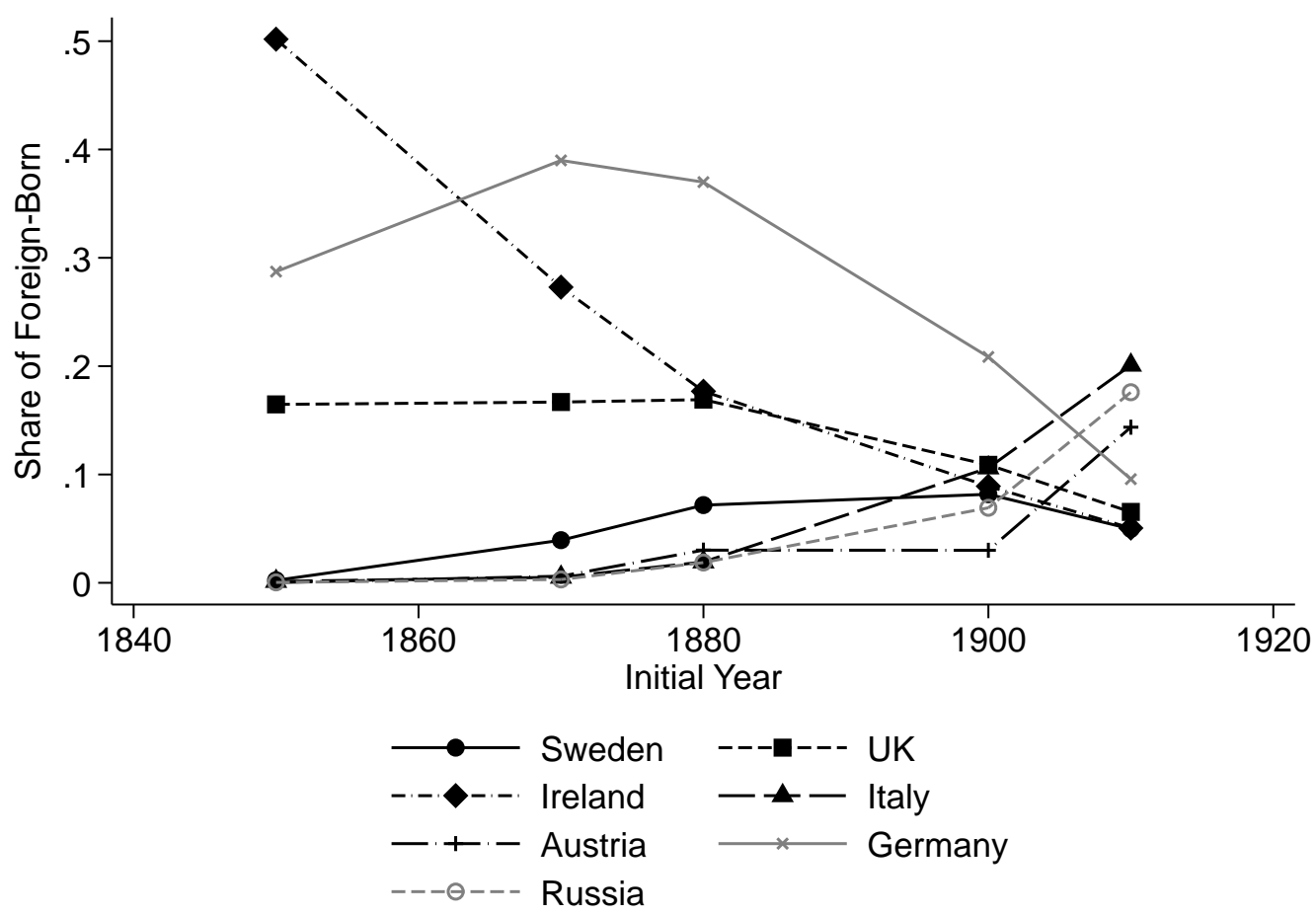

Notes: This figure presents the share of immigrants in each of our linked samples from each country of origin, limiting attention to the largest groups. Observations weighted to correct for selection into linkage. The year on the $x$-axis represents the initial year of the linked sample. "Austria" refers to the Austro-Hungarian Empire. 
Figure 4: Occupational distributions

Figure 4(a): Initial Year 1850

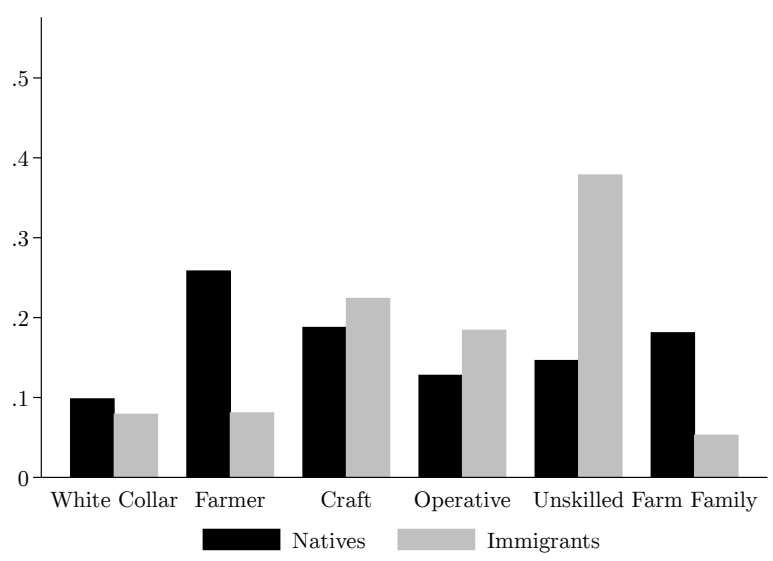

Figure 4(c): Initial Year 1870

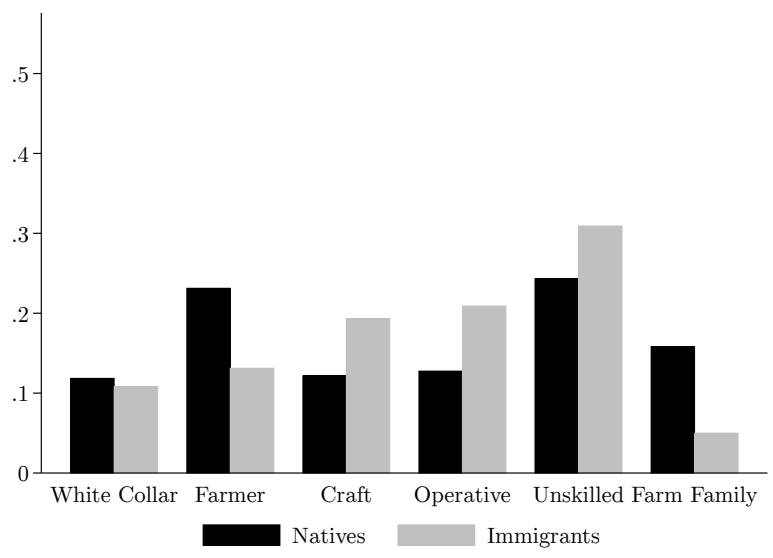

Figure 4(e): Initial Year 1880

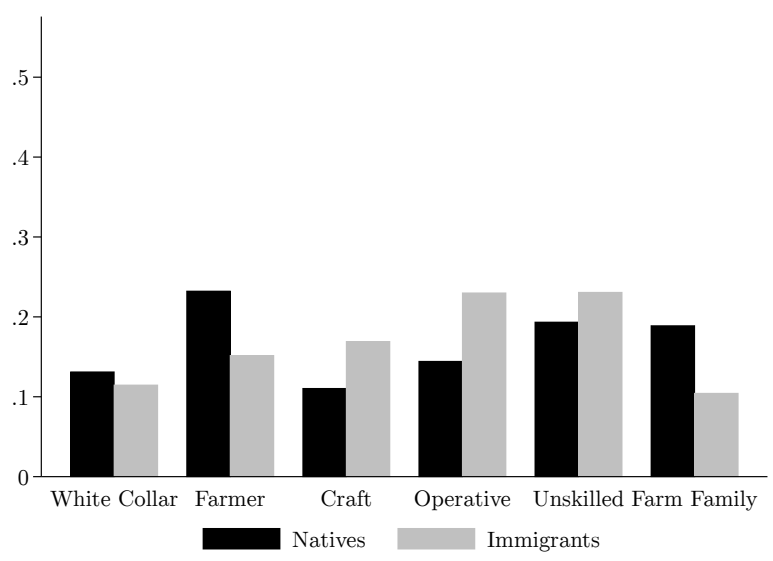

Figure 4(b): Final Year 1880

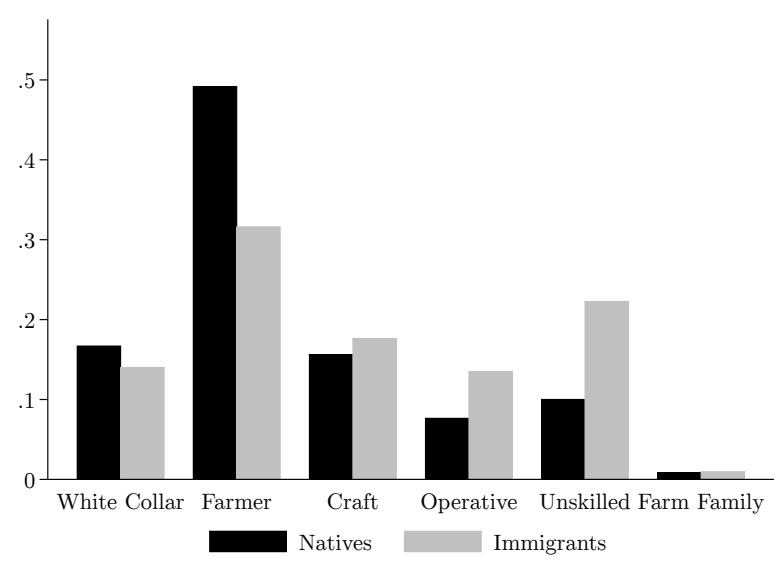

Figure 4(d): Final Year 1900

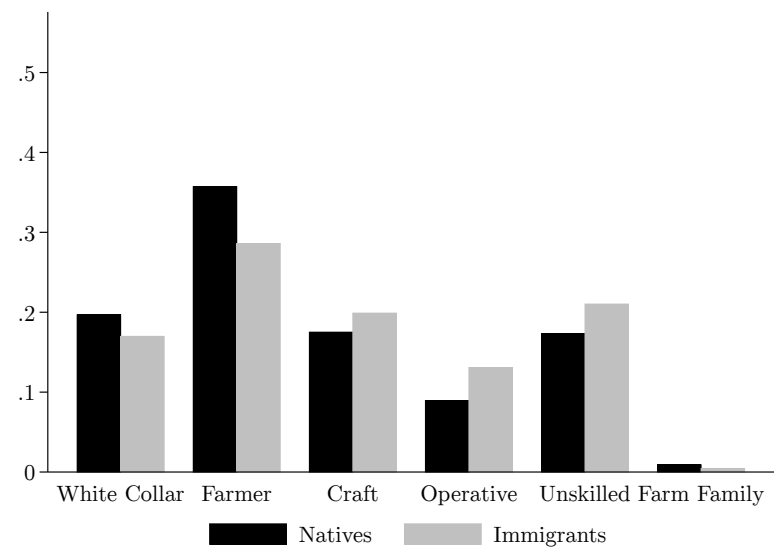

Figure 4(f): Final Year 1910

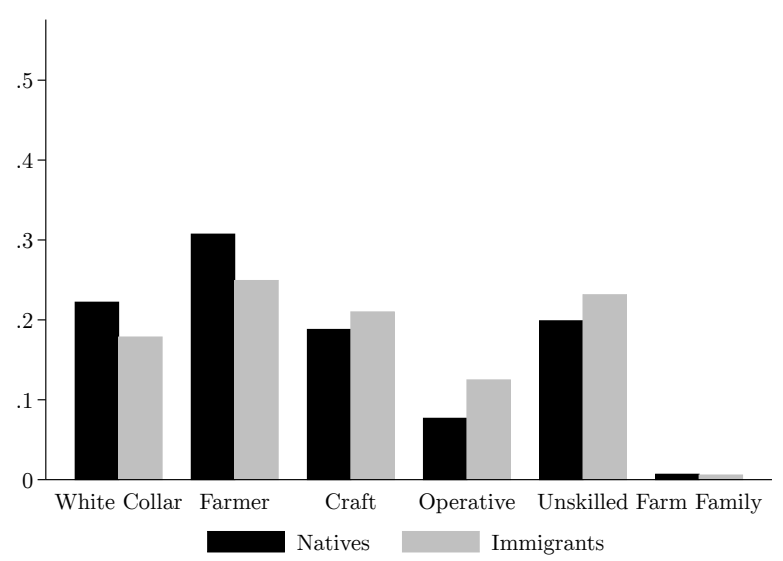


Figure 4 (continued): Occupational distributions

Figure 4(g): Initial Year 1900

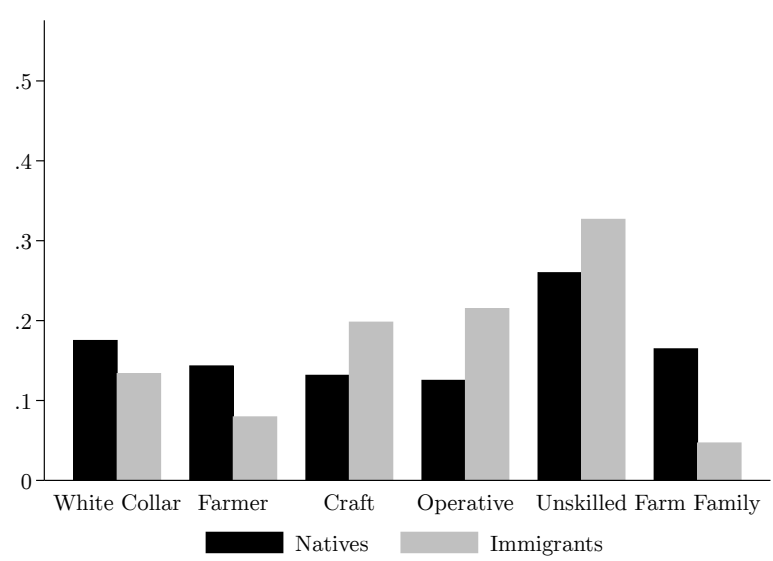

Figure 4(i): Initial Year 1910

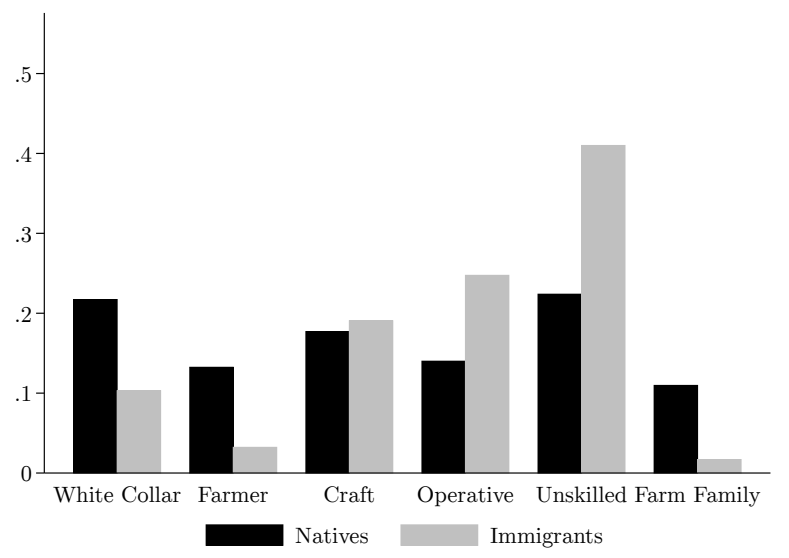

Figure 4(h): Final Year 1930

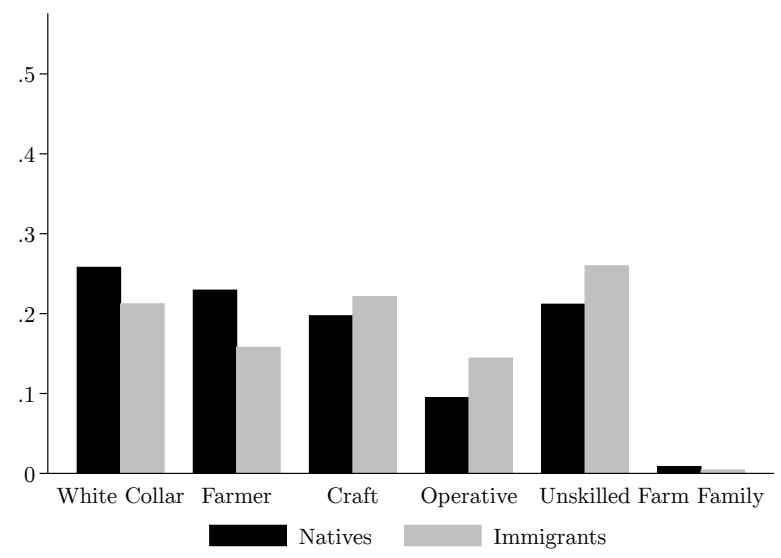

Figure 4(j): Final Year 1940

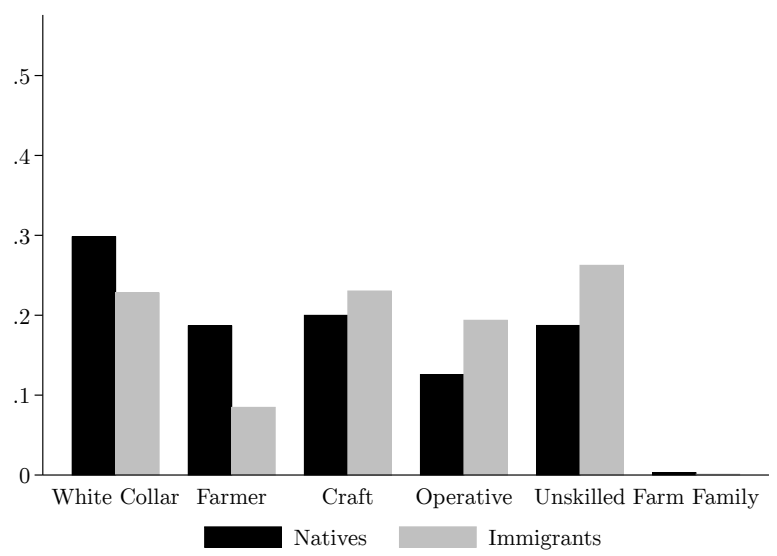

Notes: These graphs show the occupational distribution of natives and immigrants in each year using inverseprobability weights to correct for selection into linkage. Occupational categories are defined as in text. Sample limited to individuals with occupations in both years. 
Figure 5: Initial gaps in occupational rank

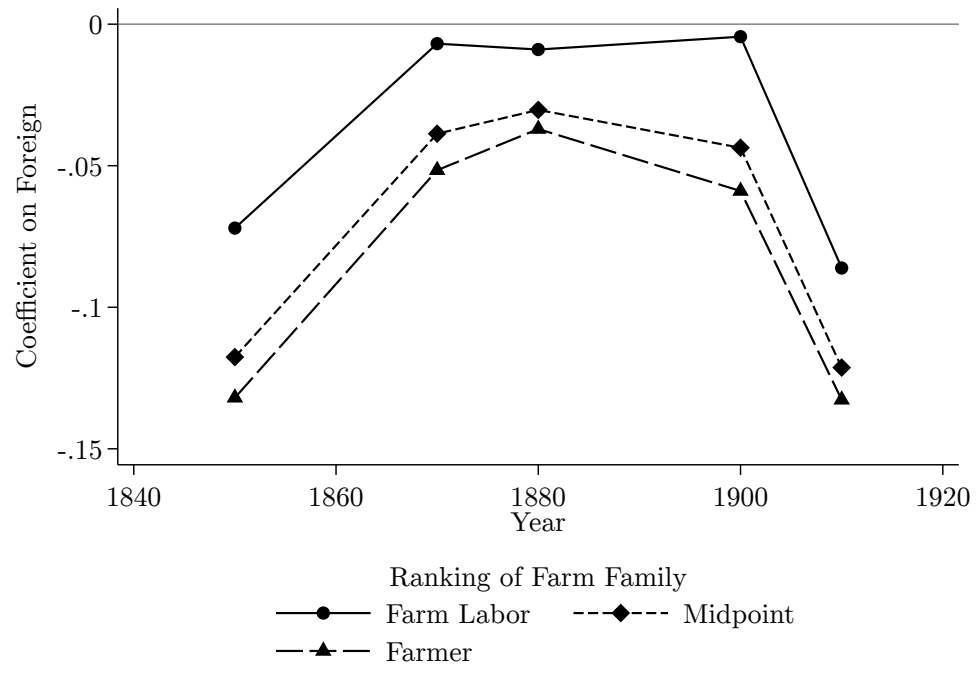

Notes: This figure presents the initial difference in the average occupational rank measure between immigrants and natives. The year on the $x$-axis is an initial year for one of our five linkage spans. The three lines each represent one potential ranking for farm family members. A negative coefficient corresponds to immigrants ranking behind natives. Observations corrected for selection into linkage. Online Appendix Table A.4 presents these estimates and their standard errors in full.

Figure 6: Dissimilarity indices

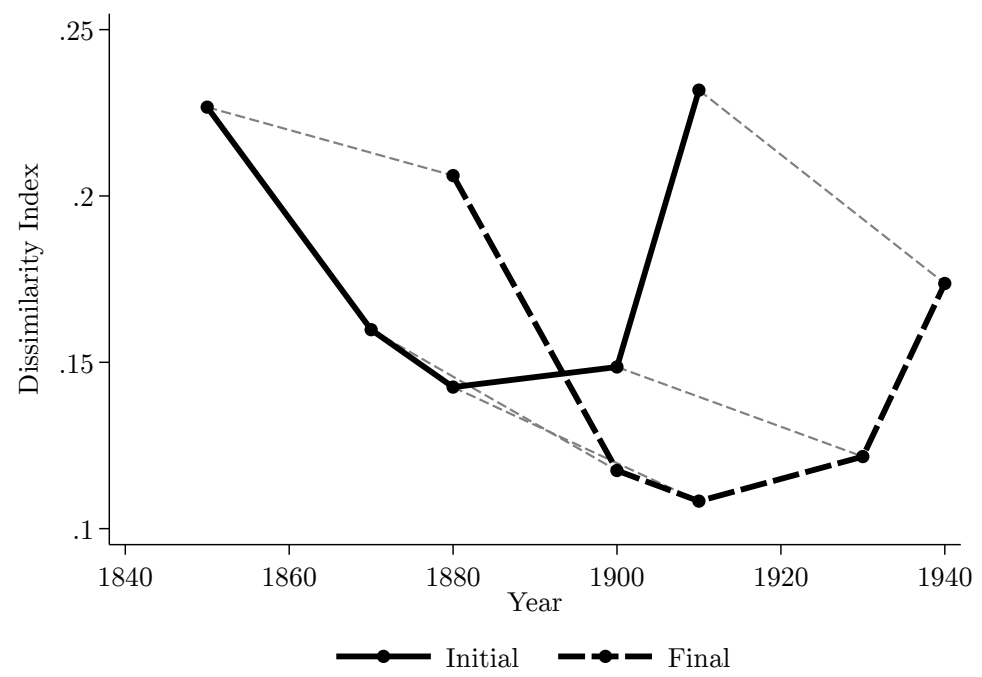

Notes: This figure presents age-adjusted dissimilarity indices for all initial and final years of linkage spans. The thin dashed lines linking the "initial" and "final" lines link the initial year of a linkage span to its final year. Observations weighted to correct for selection into linkage. Online Appendix Table A.2 presents these estimates and their standard errors. 
Figure 7: Unconditional assimilation

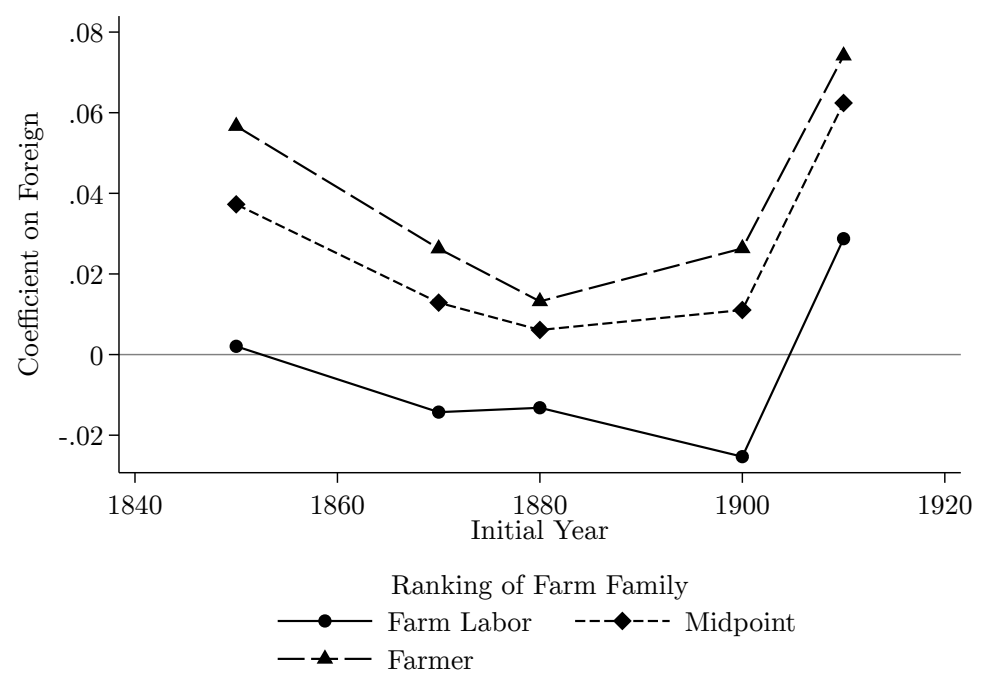

Notes: This figure presents unconditional immigrant assimilation in terms of the average rank measure. The year on the $x$-axis represents the initial year of the linkage span. The three series represent the results for each of our three rankings of farm family members. Observations weighted to correct for selection into linkage. Full results are presented in Online Appendix Table A.4.

Figure 8: Conditional assimilation

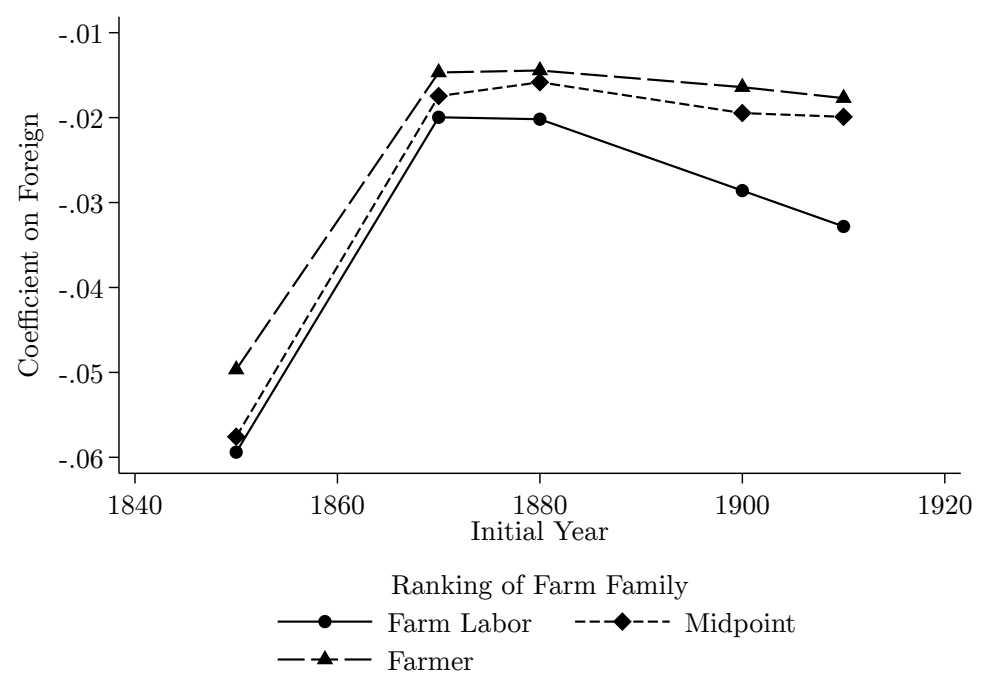

Notes: This figure presents conditional immigrant assimilation in terms of the average rank measure. The year on the $x$-axis represents the initial year of the linkage span. The three series represent the results for each of our three rankings of farm family members. Observations weighted to correct for selection into linkage. Full results are presented in Online Appendix Table A.5. 
Figure 9: Occupational upgrading by initial occupation

Figure 9(a): 1850-1880

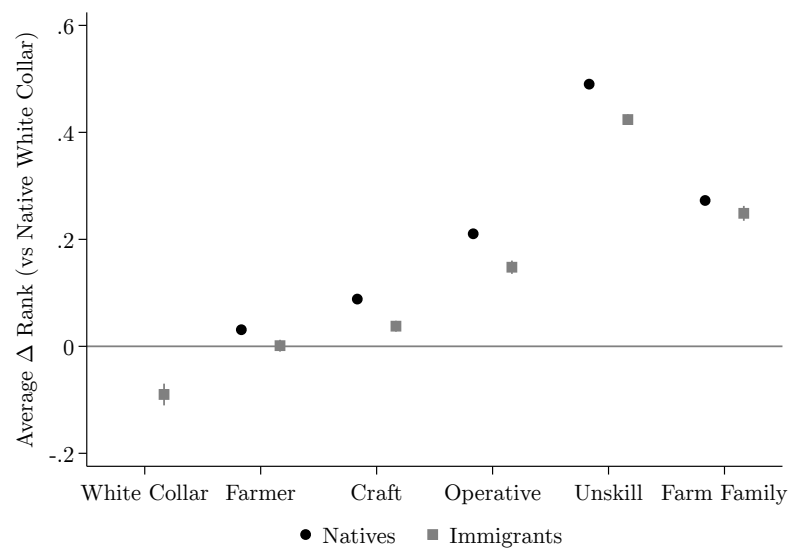

Figure 9(c): 1880-1910

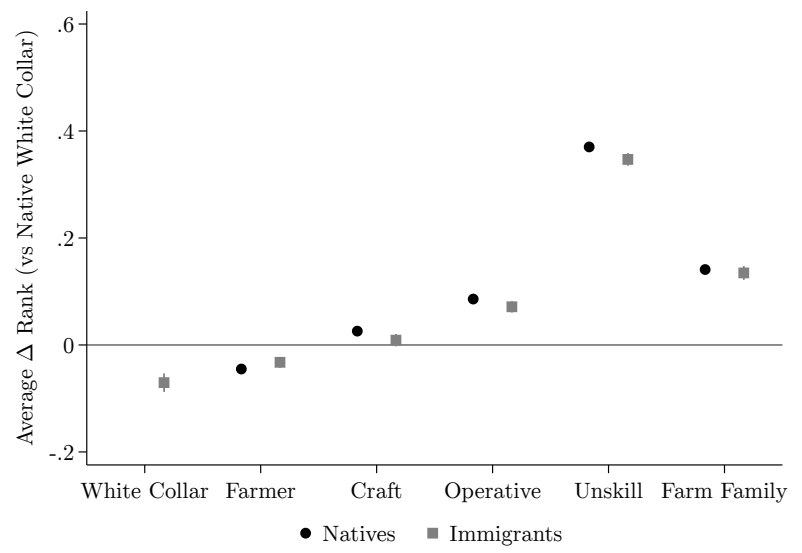

Figure 9(b): 1870-1900

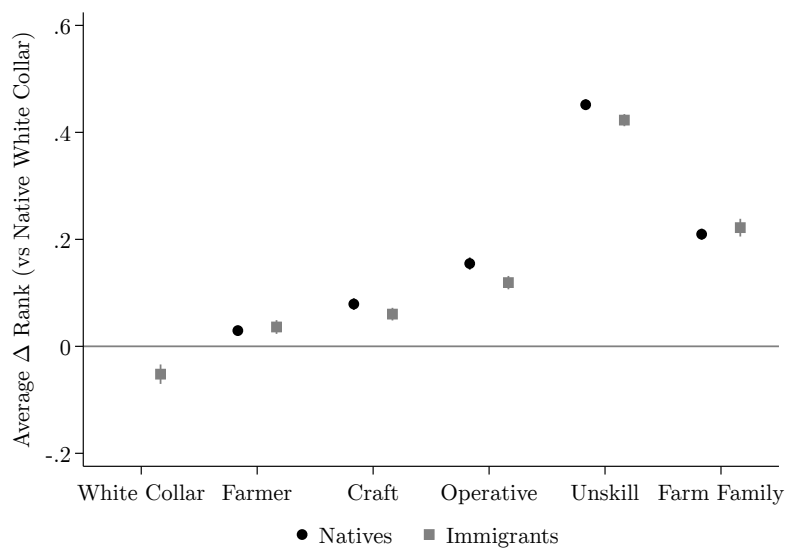

Figure 9(d): 1900-1930

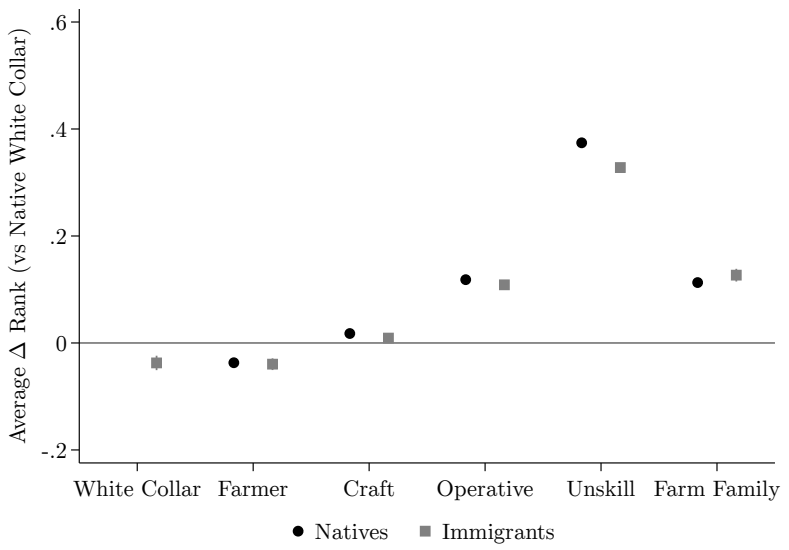

Figure 9(e): 1910-1940

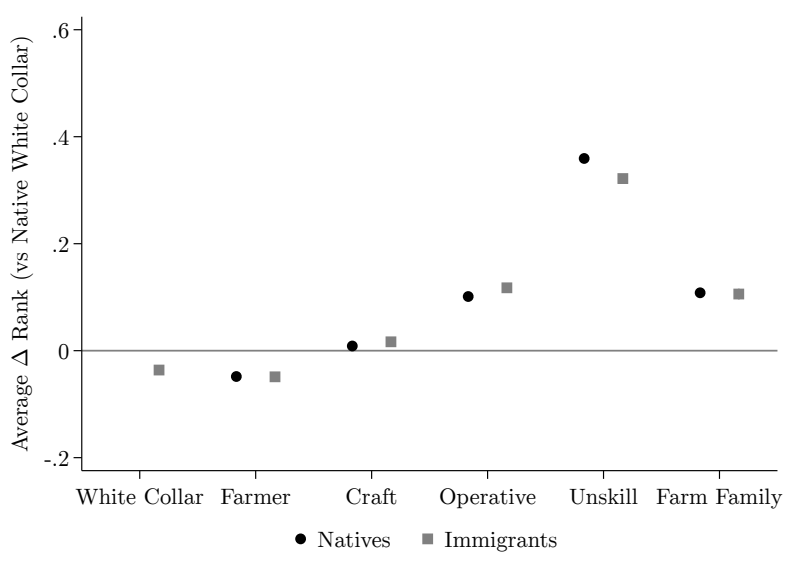

Notes: These graphs express the average upgrading experienced by immigrants or natives in each initial occupational category, expressed relative to natives initially in white collar occupations. Farm family members are ranked at the midpoint of farmers and farm laborers. Observations weighted to correct for selection into linkage. The figures include 95-percent confidence intervals, but these are often so small that they are obscured by the markers. Additional results in Online Appendix Figures A.1 and A.2. 
Figure 10: Unconditional assimilation, holding upgrading constant

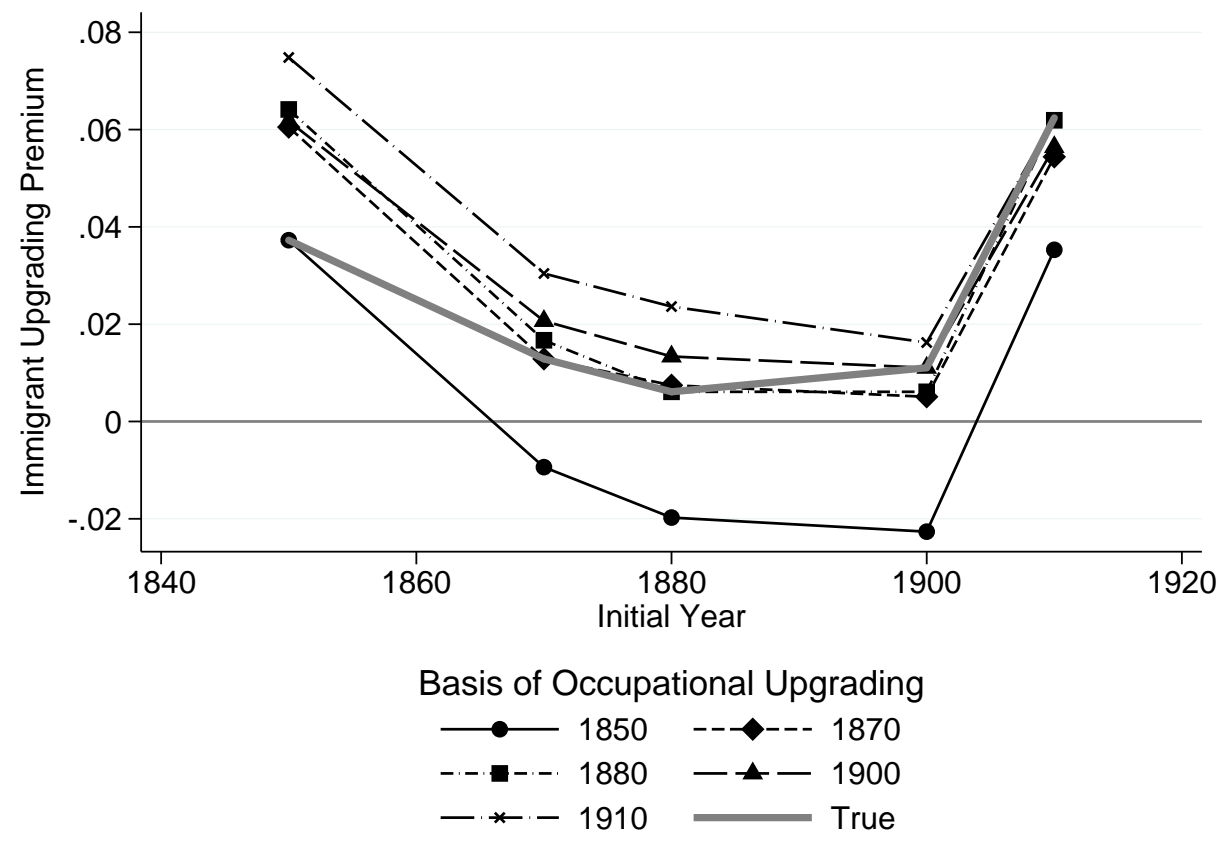

Notes: Each line shows the occupational upgrading that would have occurred with fixed occupational upgrading, allowing the occupational weights to change over time. The legend indicates which initial year's occupational upgrading is used. The $x$-axis indicates the initial year of the 30 -year span from which the initial occupation weights are taken. The $y$-axis shows the difference in occupational upgrading between immigrants and natives over the period; positive numbers indicate that foreigners upgraded more than natives. Farm family members are ranked at the midpoint of the rankings of farmers and farm laborers. Observations weighted to correct for selection into linkage. Additional results in Online Appendix Figure A.3. 
Figure 11: Unconditional assimilation, holding initial occupational distributions constant

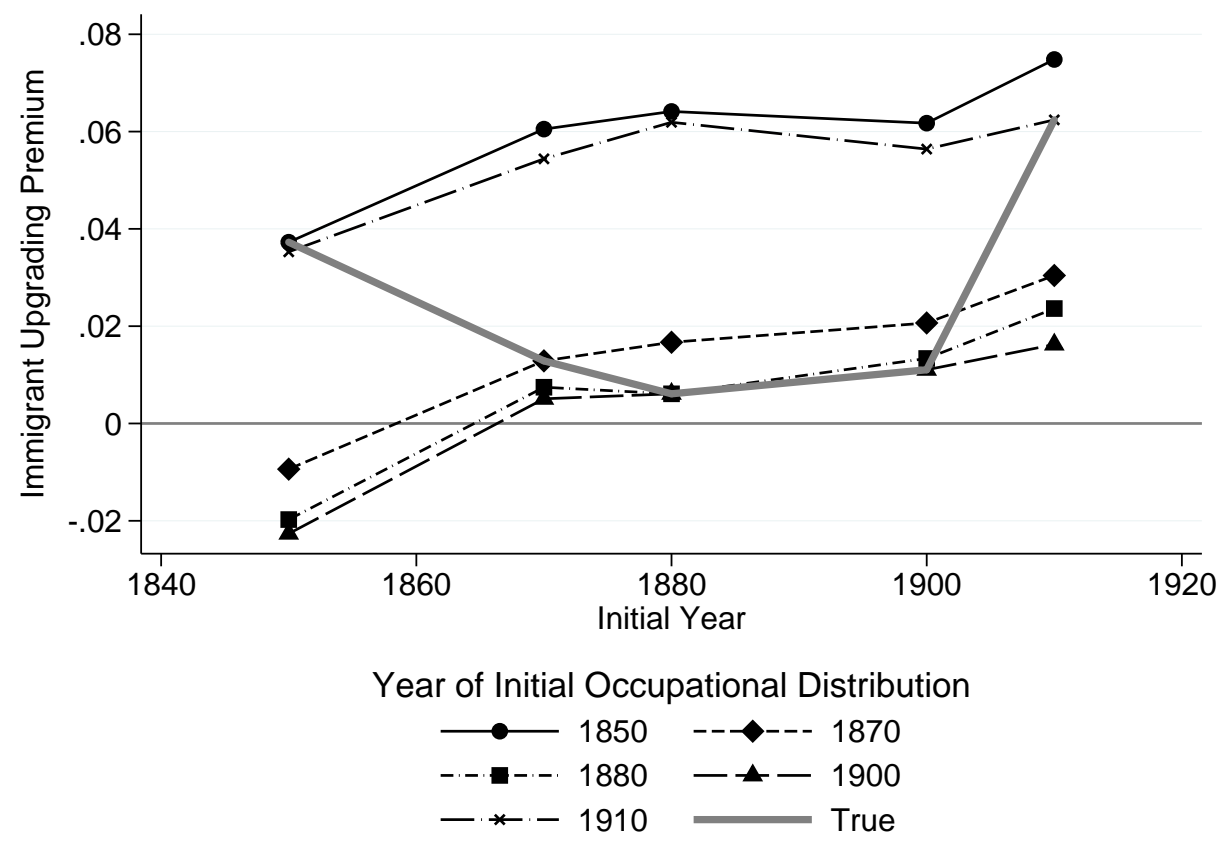

Notes: Each line shows the occupational upgrading that would have occurred with fixed occupational weights, allowing the occupational upgrading to change over time. The legend indicates which initial year's occupational weights are used. The $x$-axis indicates the initial year of the 30 -year span from which the initial occupation-specific upgrading is taken. The $y$-axis shows the difference in occupational upgrading between immigrants and natives over the period; positive numbers indicate that foreigners upgraded more than natives. Farm family members are ranked at the midpoint of the rankings of farmers and farm laborers. Observations weighted to correct for selection into linkage. Additional results in Online Appendix Figure A.4. 
Figure 12: Unconditional assimilation, holding nationality distributions constant

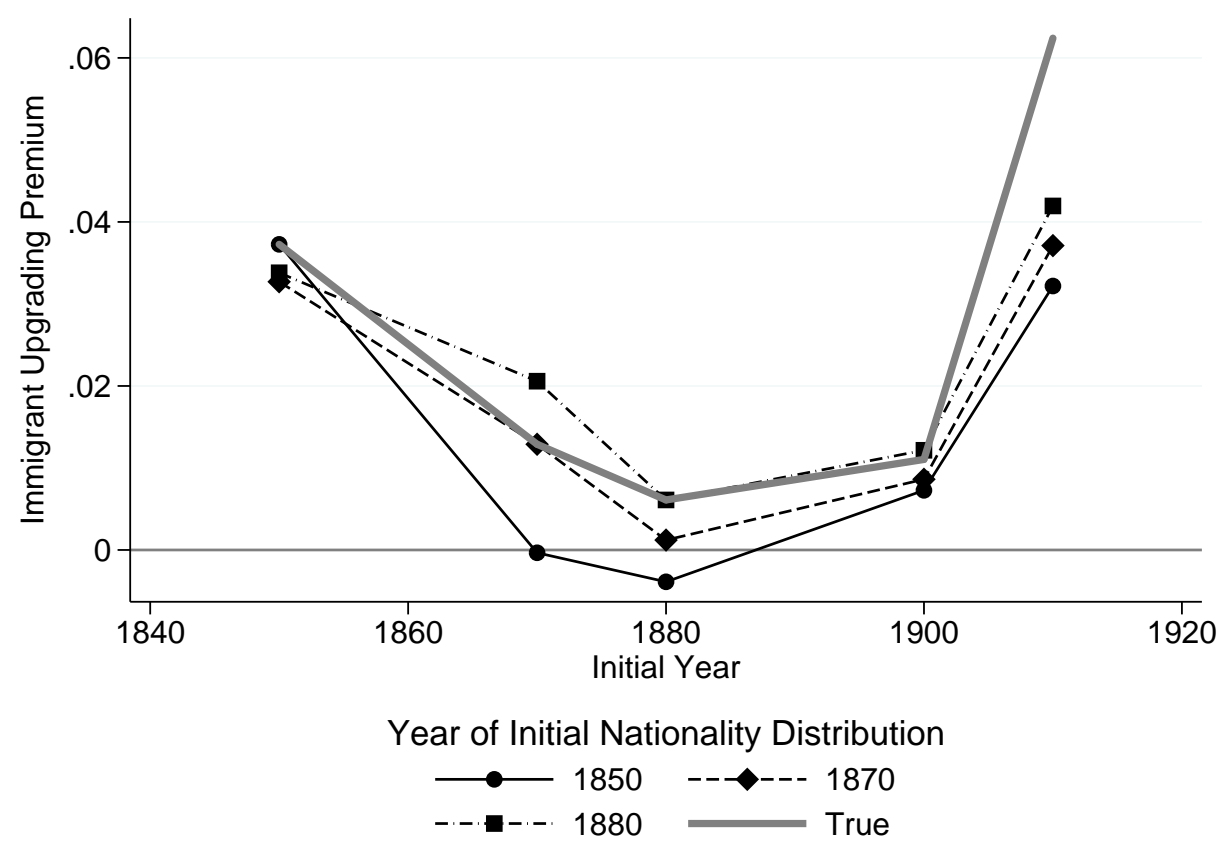

Notes: Each line shows the occupational upgrading that would have occurred with fixed nationality distributions, allowing the occupational weights and occupational upgrading to change over time. The legend indicates which initial year's nationality distribution is used. The $x$-axis indicates the initial year of the 30 -year span from which the initial occupation weights and initial occupation-specific upgrading are taken. The $y$-axis shows the difference in occupational upgrading between immigrants and natives over the period; positive numbers indicate that foreigners upgraded more than natives. Farm family members are ranked at the midpoint of the rankings of farmers and farm laborers. Observations weighted to correct for selection into linkage. Additional results in Online Appendix Figure A.5. 